\title{
Engineering Properties of Concrete with Waste Recycled Plastic: A Review
}

\author{
Adewumi John Babafemi ${ }^{1}\left(\mathbb{D}\right.$, Branko Šavija $^{2, *}$ (D), Suvash Chandra Paul ${ }^{3} \mathbb{D}$ and \\ Vivi Anggraini ${ }^{3} \mathbb{D}$ \\ 1 Department of Building, Faculty of Environmental Design and Management, Obafemi Awolowo University, \\ Ile-Ife 220282, Nigeria; ajbabafemi@oauife.edu.ng \\ 2 Microlab, Faculty of Civil Engineering and Geosciences, Delft University of Technology, \\ Delft 2628CN, The Netherlands \\ 3 Civil Engineering, School of Engineering, Monash University Malaysia, Bandar Sunway 47500, Malaysia; \\ suvash.chandra@monash.edu (S.C.P.); vivi.anggraini@monash.edu (V.A.) \\ * Correspondence: b.savija@tudelft.nl; Tel.: +31-15-278-8741
}

Received: 25 September 2018; Accepted: 23 October 2018; Published: 25 October 2018

check for updates

\begin{abstract}
The abundance of waste plastic is a major issue for the sustainability of the environment as plastic pollutes rivers, land, and oceans. However, the versatile behavior of plastic (it is lightweight, flexible, strong, moisture-resistant, and cheap) can make it a replacement for or alternative to many existing composite materials like concrete. Over the past few decades, many researchers have used waste plastic as a replacement for aggregates in concrete. This paper presents a comprehensive review of the engineering properties of waste recycled plastic. It is divided into three sections, along with an introduction and conclusion. The influence of recycled waste plastics on the fresh properties of concrete is discussed first, followed by its influence on the mechanical and durability properties of concrete. Current experimental results have shown that the mechanical and durability properties of concrete are altered due to the inclusion of plastic. However, such concrete still fulfills the requirements of many engineering applications. This review also advocates further study of possible pre-treatment of waste plastic properties for the modification of its surface, shape, and size in order to improve the quality of the composite product and make its use more widespread.
\end{abstract}

Keywords: waste plastic concrete; fresh properties; mechanical properties; durability

\section{Introduction}

Presently, different types of waste materials and industrial byproducts such as recycled concrete aggregate, glass, ceramic, fly ash, slag, etc., are being used with and without natural aggregates and ordinary Portland Cement (OPC), not only in traditional construction but also in digital construction like 3D printing [1-3]. It has been shown that the properties of these materials are suitable to produce new concrete up to a certain limit. Therefore, numerous studies have been conducted to find the optimum content of these materials in concrete, which does not negatively influence the engineering properties of concrete. Waste materials such as plastics and glass, which present possible environmental hazards and are often landfilled, are often used in concrete for different applications [4-6]. Globally, the use of plastics had seen an astronomical increase since 1920, when it was first developed for industrial use. The many advantages of plastics have caused the increase in its production by plastic industries. Compared to other materials such as glass and metal, plastics have lower cost, a higher strength-to-weight ratio, are more durable (resistant to deterioration), easy to work and shape, and have a low density. Some staggering statistics have shown that in 2013, 299 million tons of plastic were produced globally [5,6], exceeding the estimated consumption for 2015 by about 
2 million tons [7]. However, waste plastics are generally a threat to the global environment. While the production of plastics in its varied forms cannot be halted, recycling may be a solution to the threat waste plastics pose to the environment.

Recycling of various types of organic and inorganic waste such as construction, electronics, and agricultural waste, among others, has drawn much attention due to the increasing cost of dumping the waste and decreasing space in landfills [8]. Again, the recycling of all sorts of waste materials is sustainable and conserves natural resources. Millions of tons of plastic waste are generated all around the world, and they frequently find their way into rivers, coast, beaches, and the land $[8,9]$. Only about $25 \%$ of plastic waste is recycled around the world. Recovery and recycling of plastics remain insufficient, and millions of tons end up in landfills and oceans every year [10]. This percentage of recycled plastic can be increased by transforming waste plastic into products suitable for housing and construction [5]. Figure 1 illustrates the cumulative amount of plastic waste generation and disposal from 1950 up to 2015 and the projected amount by 2050. Up to 2015, only about $16 \%$ of the waste generated was recycled. It is projected that by 2050 , up to $33 \%$ of the waste generated will be recycled. Even if this projection comes true, the amount of unrecycled waste will still leave much to be desired.

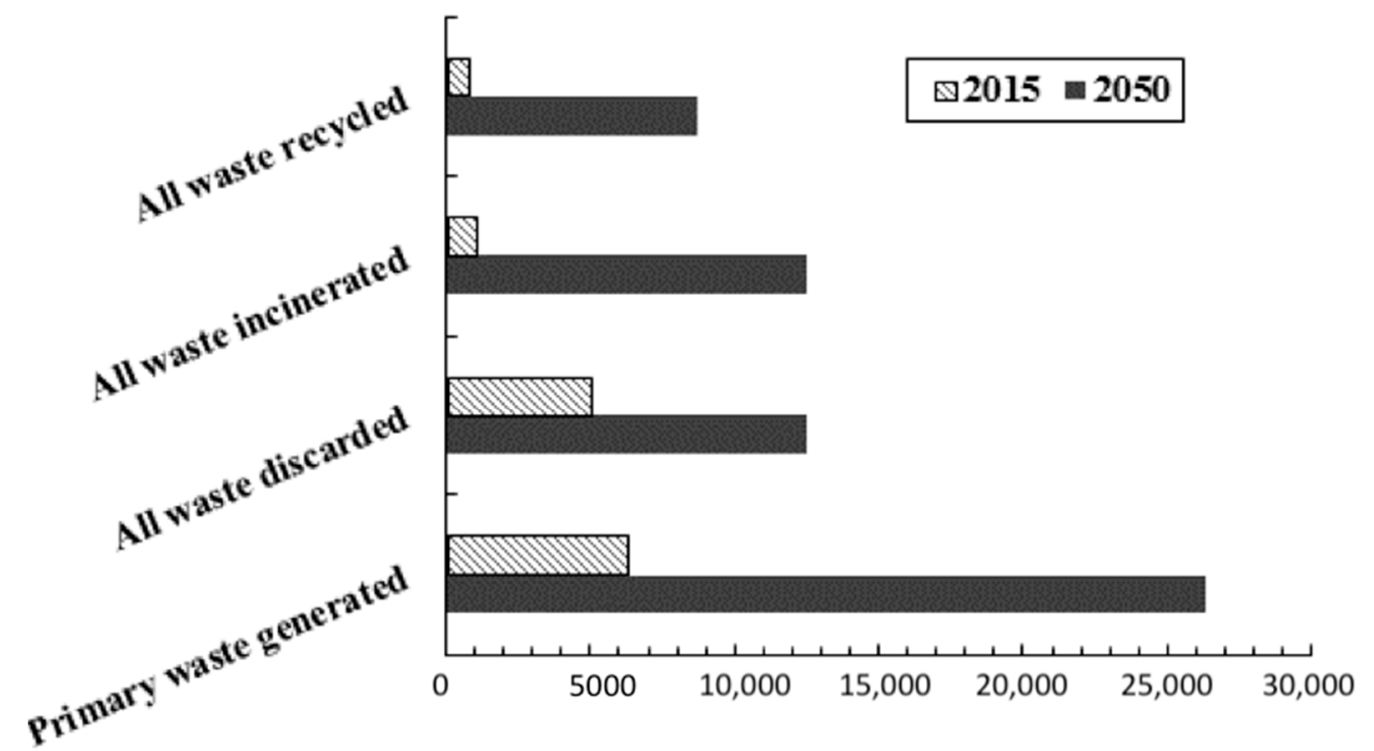

Million metric tons

Figure 1. Cumulative plastic waste generation and disposal (historical data up to 2015 and projection data up to 2050) [7].

A major challenge with plastic waste is that it may consist of mixed organic (food remains) and inorganic (attached paper level) fractions, which makes it a complex stream to recycle [6]. However, a possible solution would be to use it as aggregates in concrete for various applications where contamination of plastic waste would not make any significant difference to the concrete properties. With global production of more than 5.3 billion cubic meters per year [11], there may be a huge potential for using recycled plastics in concrete. Consequently, significant use of waste plastics as aggregate in concrete may further reduce the amount of unrecycled plastic waste. However, while a large variety of plastic types such as polyethylene terephthalate (PET), polylactic acid (PLA), polypropylene (PP), high-density polyethylene (HDPE), polyvinyl chloride (PVC), low-density polyethylene/linear low-density polyethylene (LDPE/LLDPE), polystyrene (PS), and other resins [9] are available on the market, research has shown that not all of them are suitable for use as aggregates in concrete. Resin-based types of waste plastic and PET have been reported to have the highest rate of use for concrete production [12-14]. Other types have only been recycled to a small extent or not recycled at all. 
In most cases, waste plastics have been used in concrete either as fine or coarse aggregate. Although utilization of this type of waste in concrete is beneficial from an environmental point of view, its engineering (e.g., mechanical and thermal) properties are essentially different from natural aggregates (Table 1). It is also worth noting that the properties of recycled waste plastic concrete depend on the pre-treatment given to the waste plastic. The bond strength of plastic aggregates and the cement paste could be significantly influenced by the treatment.

Table 1. Some properties of common plastic materials and cementitious materials (adapted from [15]).

\begin{tabular}{cccc}
\hline Material & $\begin{array}{c}\text { Elastic Modulus } \\
(\mathbf{G P a})[16-18]\end{array}$ & $\begin{array}{c}\text { Tensile Strength } \\
\mathbf{( M P a )}[\mathbf{1 6}]\end{array}$ & $\begin{array}{c}\text { Thermal Conductivity } \\
\mathbf{( W / m K )}[\mathbf{1 7}, \mathbf{1 9}]\end{array}$ \\
\hline PET & $2.1-3.1$ & $55-80$ & 0.15 \\
PE & $0.6-1.4$ & $18-30$ & $0.33-0.52$ \\
PVC & $2.7-3.0$ & $50-60$ & $0.17-0.21$ \\
PP & $1.3-1.8$ & $25-40$ & 0.12 \\
PS & $3.1-3.3$ & $30-55$ & 0.105 \\
Quartzite sand & 70 & - & 4.45 \\
Limestone gravel & 70 & - & $2.29-2.78$ \\
Cement paste (w/c $=0.5)$ & $15-20$ & - & 1 \\
\hline
\end{tabular}

Furthermore, the intrinsic behavior of waste plastic such as low fire resistance, surface roughness, and shape can significantly alter the properties of concrete. Consequently, much research has been devoted to studying the influence of waste plastics in concrete in the past three decades (Figure 2). A list of different types of waste plastics and their influences on different concrete properties, as examined by various researchers, is given in Table 2. It can be seen that the number of articles has increased almost tenfold during this period. However, a number of issues are still not solved.

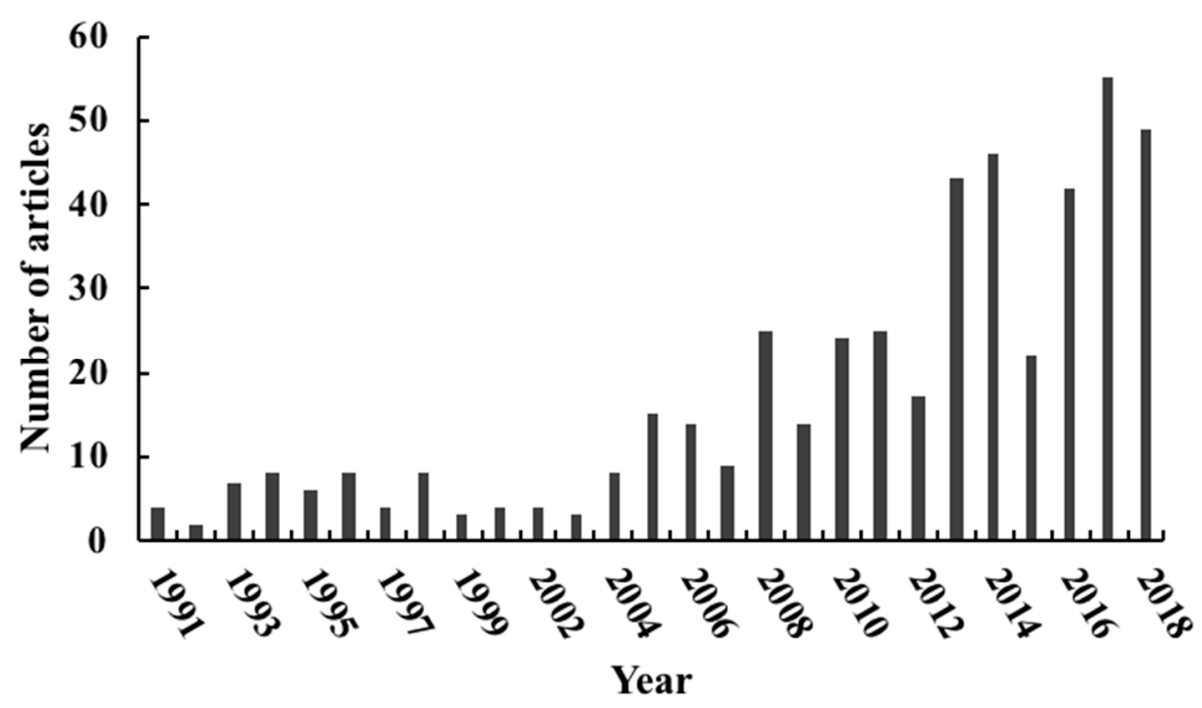

Figure 2. Number of scientific articles published on the use of PET plastics in cementitious materials (according to SCOPUS, accessed on 7 September 2018, search terms "PET AND concrete OR mortar").

Utilization of recycled waste plastics in concrete as a partial aggregate replacement has a clear effect on the properties of the material. Therefore, if this material is to be used in concrete in large quantities, it is important to know the relationship between the addition of recycled waste plastics and the engineering properties. This review provides a basis for understanding this relationship.

A thorough search of peer-reviewed literature was undertaken to find studies in which recycled plastic has been used for the production of concrete. Major search engines (ScienceDirect, Google Scholar) were used. The focus was on recent literature, i.e., published after 2010, relevant to current developments in the field. Articles from reputable journals dealing with building materials on 
the one hand and sustainable development and recycling on the other hand were extracted. Note that the number of citations of individual articles was not used as a selection criterion; instead, articles were selected based on their relevance to (parts of) this review. After collecting the relevant articles, we then categorized into those dealing with fresh, mechanical, and durability properties of concrete. Thereafter, each property was reviewed from the different publications, and a position statement was arrived at by these authors. Where differences or similarities exist, these were discussed extensively. The purpose of the paper is to present clearly, from experimental results, the performance of concrete containing recycled waste plastic regarding the fresh, mechanical, and durability properties. Therefore, this paper can be used as a valuable source of data for researchers for their future studies since it critically summarizes the recent findings on the use of waste plastics in concrete.

Table 2. Previous studies on different concrete properties with waste plastic.

\begin{tabular}{|c|c|c|c|c|c|c|}
\hline Author & $\begin{array}{l}\text { Concrete } \\
\text { /Mortar }\end{array}$ & $\begin{array}{l}\text { Type of } \\
\text { Plastic } \\
\text { Waste }\end{array}$ & $\begin{array}{c}\text { Plastic } \\
\text { Waste } \\
\text { Replacement }\end{array}$ & $\begin{array}{l}\text { Size of the } \\
\text { Particle } \\
(\mathrm{mm})\end{array}$ & $\begin{array}{l}\text { Water-Cement } \\
\text { Ratio }\end{array}$ & Properties \\
\hline [20] & Concrete & $\begin{array}{l}\text { Metallic } \\
\text { plastic as } \\
\text { fiber }\end{array}$ & $\begin{array}{l}0.5 \%, 1 \%, \\
1.5 \%, 2 \%\end{array}$ & $\begin{array}{l}\text { length } 5 \text { to } \\
20\end{array}$ & 0.45 & $\begin{array}{c}\text { Impact load, corrosion, weight loss, } \\
\text { sulphate attack, } \\
\text { oxygen permeability }\end{array}$ \\
\hline [21] & Concrete & E-plastic & $\begin{array}{l}5 \%, 15 \% \\
25 \%\end{array}$ & 2 to 8 & - & $\begin{array}{l}\text { Comp. strength, flexural strength, } \\
\text { splitting strength, }\end{array}$ \\
\hline [22] & Concrete & PET & $\begin{array}{l}20 \%, 30 \% \\
40 \%, 50 \%\end{array}$ & 5 to 12 & $\begin{array}{l}0.42,0.48 \\
\quad 0.57\end{array}$ & $\begin{array}{l}\text { Workability, density, } \\
\text { comp. strength }\end{array}$ \\
\hline [23] & Concrete & E-plastic & $\begin{array}{l}5 \%, 10 \% \\
15 \%\end{array}$ & 10 to 20 & 0.5 & $\begin{array}{l}\text { Comp. strength, splitting strength, } \\
\text { porosity, water absorption }\end{array}$ \\
\hline [24] & Concrete & - & $\begin{array}{r}25 \%, 50 \% \\
75 \%, 100 \% \\
\end{array}$ & 1 to 10 & 0.5 & $\begin{array}{l}\text { Workability, density, } \\
\text { comp. strength }\end{array}$ \\
\hline [25] & Concrete & PET & $\begin{array}{l}5 \%, 10 \% \\
15 \%\end{array}$ & 0.15 to 7 & $0.42,0.54$ & $\begin{array}{l}\text { Comp. strength, flexural strength, } \\
\text { elastic modulus, UPV }\end{array}$ \\
\hline [26] & Concrete & PET & $7.5 \%, 15 \%$ & 3 to 10 & 0.51 to 0.61 & $\begin{array}{c}\text { Comp. strength, splitting strength, } \\
\text { modulus of elasticity, } \\
\text { abrasion resistance, }\end{array}$ \\
\hline [27] & Concrete & E-plastic & $\begin{array}{c}4 \%, 8 \%, 12 \% \\
16 \%, 20 \% \\
24 \%\end{array}$ & 1.86 to 2.78 & - & $\begin{array}{l}\text { Comp. strength, } \\
\text { sorptivity, permeability }\end{array}$ \\
\hline [28] & Mortar & PET \& PC & $\begin{array}{l}3 \%, 10 \% \\
20 \%, 50 \%\end{array}$ & 1.6 to 10 & 0.5 & $\begin{array}{l}\text { Comp. strength, flexural strength, } \\
\text { elastic modulus, water absorption }\end{array}$ \\
\hline [29] & Concrete & PET & $10 \%, 20 \%$ & 0.26 to 1.14 & $0.5,0.6$ & $\begin{array}{c}\text { Comp. strength, flexural strength, } \\
\text { water absorption, UPV }\end{array}$ \\
\hline
\end{tabular}

\section{Fresh Properties of Concrete with Recycled Plastics}

Concrete remains in its fresh state from the time of mixing until it sets. In the fresh state, utmost attention is usually giving to handling, placement, and compaction. The hardened properties of concrete are related to its fresh state since the consistency of the fresh concrete gradually decreases from the time mixing is completed. Furthermore, the consistency and compaction of the mix are vital for the potential strength and durability of concrete. The most important properties of fresh concrete are thus associated with its workability and consistency. When recycled or waste plastics are introduced as either fine or coarse aggregate in a concrete mix, the fresh properties of concrete could be significantly altered. This section highlights the fresh properties of concrete containing recycled and waste plastics as fine and coarse aggregates. 


\subsection{Workability}

Concrete slump is commonly used to define the workability of the fresh mix. Factors such as particle size grading, the shape of particles, the water-cement ratio, and the amount of plasticizer in the mix are directly related to the concrete workability. Various researchers have investigated and reported the influence of recycled and waste plastics as fine and coarse aggregates (recycled and waste plastic aggregates-RWPA) on the workability of concrete [21,30-33]. Research findings have shown conflicting performances of concrete workability under the influence of RWPA, as demonstrated in Figure 3.

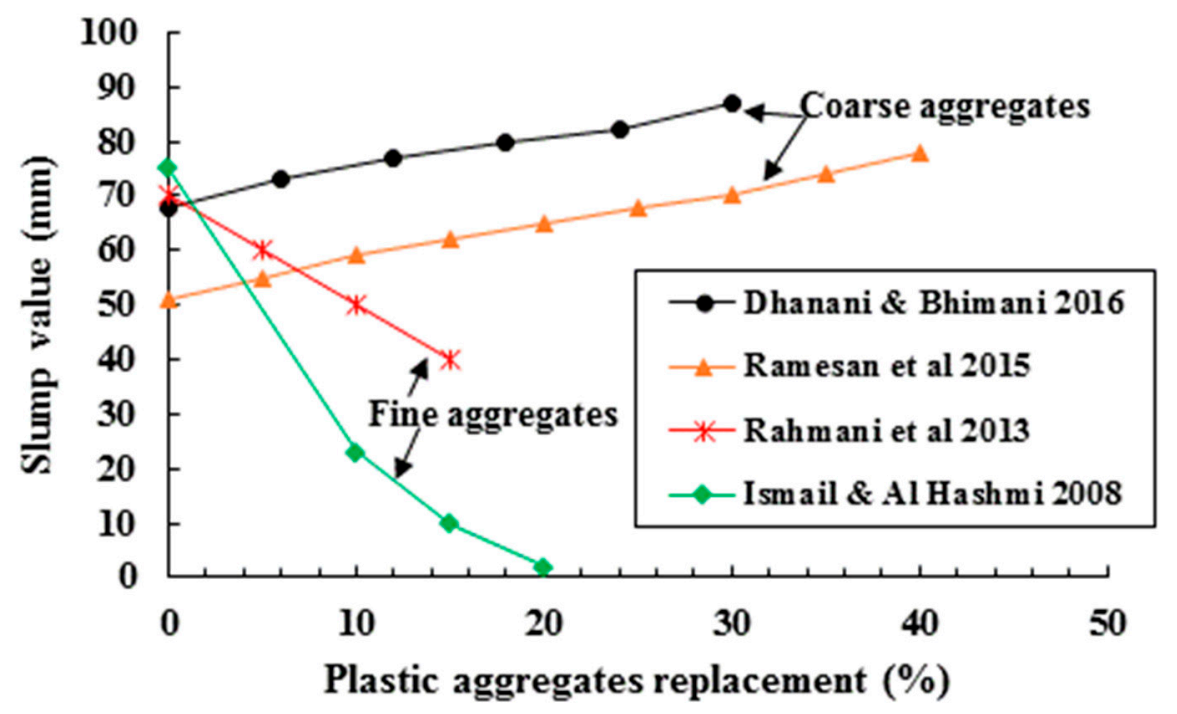

Figure 3. Influence of coarse and fine plastic aggregates ion the concrete slump.

In the studies conducted by Dhanani and Bhimani [34] and Ramesan and Babu [35], where RWPA were used as coarse aggregate in the concrete, the results showed that the slump of concrete increased as the percentage of RWPA increased up to $40 \%$ (Figure 3). The increase in the slump shows that as the quantity of natural coarse aggregates decreased, and the quantity of recycled plastics increased, more water was made available from the mix due to reduced absorption by decreasing the quantity of natural aggregates, and low water absorption by recycled plastics [24,36]. Tang et al. [37] reported a similar increase in the slump of coarse plastic aggregate lightweight concrete at a replacement level up to $40 \%$. An increase in slump was also found for somewhat higher replacement values (50\%) by [22]. However, workability was found to decrease slightly at $60 \%$ and $80 \%$ plastic aggregate contents [34].

When sand was replaced by fine RWPA [25,38], an opposite trend in workability to that of coarse RWPA is observed, as shown in Figure 3. The slump of the concrete decreases as the fine RWPA content increases. Similar results have also been reported by Batayneh et al. [39] and Rai et al. [40]. Conversely, increases in the slump of fresh concrete containing fine RWPA have been reported by Choi et al. [30] at replacement levels up to $75 \%$. Gu et al. [9] stated that whether an increase or a decrease in a slump is observed strongly depends on the particle shape of the fine RWPA. Other researchers have shown that the size and roughness of the particles also affect the slump of plastic concrete; lamellar particles were shown to promote the workability of concrete mixtures, while flaky particles tend to reduce it [26,41]. For the impact of RWPA on the fluidity of mortar, Safi et al. [42] reported that the fluidity of a self-compacting mortar increased as the plastic waste content increased up to $50 \%$ when used as a fine aggregate. They attributed the increase in fluidity to the smooth surface of the aggregate compared to sand and to the fact that the plastic could not absorb water. The same mechanism was proposed by Saikia and de Brito [43], who stated that smooth spherical PET particles increase, while rough, sharp PET particles decrease the slump. 
Furthermore, the size of the aggregate also tends to affect the workability of concrete containing fine RWPA. The effect of the replacement of natural sand by two different recycled polyethylene terephthalate (PET) particles $(2.23 \mathrm{~mm}$ and $3.34 \mathrm{~mm}$ ) at $10 \%$ and $20 \%$ on concrete slump was studied by Albano et al. [29]. The mixes containing PET with the larger particle size $(3.34 \mathrm{~mm})$ showed a lower slump when compared to the mixes with a smaller particle size of $2.23 \mathrm{~mm}$ and with a reference containing only natural sand. The rheological behavior of concrete was significantly influenced when PET was included. Figure 4a shows the typical shapes of PET particles used in the concrete by Rahmani et al. [25]. Increasing the PET content resulted in a decrease in the plasticity and consistency of the fresh concrete. It was highlighted that the granulometry of the aggregates influences the rheology of concrete. Good granulometry of aggregates reduces concrete voids, thus influencing the plasticity and consistency. This was proved by Albano et al. [29] when PET particles of $2.23 \mathrm{~mm}$ and $3.34 \mathrm{~mm}$ were blended at equal contents ( $50 \%$ to $50 \%$ ); slump was increased for the blended PET particles in concrete. Furthermore, the water-cement ratio $(\mathrm{w} / \mathrm{c})$ and the amount of cement paste also influenced the slump of concrete since the mobility of particles depends on these factors.

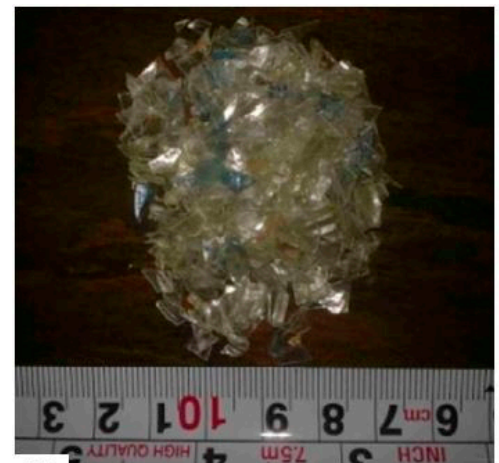
(a)
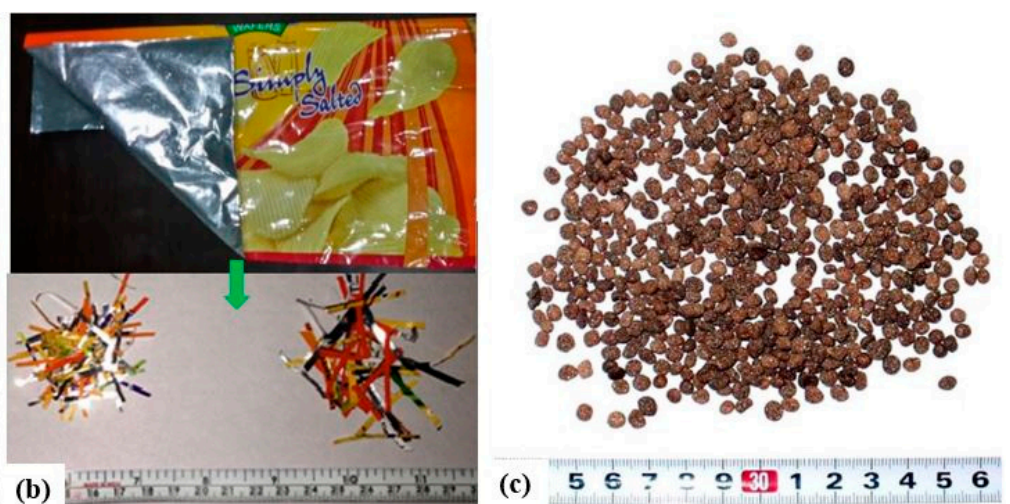

(c)

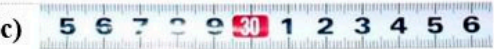

Figure 4. (a) Waste PET as aggregates; (b) metalized plastics waste (MPW) as fiber and (c) manufactured waste PET particles as fine aggregates used in concrete $[25,30,44]$.

The addition of metalized plastic waste (MPW) as fiber (as shown in Figure 4b) at different percentages $(0.5 \%, 1 \%, 1.5 \%$, and $2 \%)$ at different lengths $(5 \mathrm{~mm}, 10 \mathrm{~mm}$, and $20 \mathrm{~mm})$ in concrete was studied by Bhogayata and Arora [44]. They reported that longer fibers reduced the slump more than shorter fibers at a given fraction. Concrete containing $5 \mathrm{~mm}$ fibers length showed slump reduction by $5 \%, 8 \%, 12 \%$, and $16 \%$ for varying fractions from $0.5 \%$ to $2 \%$ (in increment of $0.5 \%$ ) when compared with the control mix without any fiber. Concrete containing $10 \mathrm{~mm}$ long fibers reduced the slump in the range between $8 \%, 12 \%, 15 \%$, and $18 \%$, and for $20 \mathrm{~mm}$ length, about $10 \%, 14 \%, 18 \%$, and $25 \%$, respectively, when compared to the $5 \mathrm{~mm}$ length [44]. It is reported that the inclusion of macrofibers affects the consistency as well as the viscosity of the fresh concrete mix [45]. Also, the higher surface area of macrofibers occupies a large portion of cement paste and leaves less paste available for aggregates, which may also lead to the lower slump of concrete. The presence of macrofibers forms a mesh-like structure adhering to the fine and coarse particles of the mix, thereby obstructing the flow of particles. Typically, a shorter length of fibers can be mixed easily with the mix constituents; therefore, the chances of forming a mesh-like structure are lower compared to with longer fibers. However, a reduction in the slump was reported at a higher fraction of shorter length of fibers.

Fresh properties of waste plastic concrete were also investigated using a V-funnel flow time test and an L-box test by Hama and Hilal [32]. Natural sand was replaced at a minimum content of $2.5 \%$ and a maximum of $12.5 \%$ by plastic aggregates in the concrete. The plastic aggregates were of two different types: coarse (passing through a $4 \mathrm{~mm}$ sieve and retained on $1 \mathrm{~mm}$ ) and fine (passing through a $1 \mathrm{~mm}$ sieve). The $\mathrm{V}$-funnel flow time increased gradually with the increase of the plastic aggregates content in the mix; more time was required for the coarse plastic aggregates than the fine aggregate. With $12.5 \%$ replacement, about $127 \%$ and $100 \%$ more time was required for coarse and fine plastic 
aggregates concrete, respectively, then the reference concrete with only natural sand. The L-box height ratio was also reduced by increasing the plastic content in the concrete. Similar to the V-funnel test, the difference of the height ratio between the control mix and the mix with fine plastic aggregates were lower than the concrete with coarse plastic aggregates. From the discussion above, it can be said that the size of the plastic aggregates significantly influences the fresh properties of concrete.

\subsection{Air Void Content}

There seems to be a paucity of studies that report the air content of concrete-containing plastic aggregate as either a fine or coarse aggregate. One of the few studies that reported the air content of concrete mixes with different percentages of fine aggregates replaced by plastic aggregate was by Chen et al. [46]. In this study, a maximum plastic aggregate size of $4 \mathrm{~mm}$ was used. The investigation showed an insignificant difference in the air contents of the various concrete mixes containing plastic aggregates up to $20 \%$ of fine aggregates. However, in comparison to the control mix (without the inclusion of any plastic aggregates), about $110 \%, 167 \%$, and $387 \%$ higher air content were found in concrete when fine aggregate was replaced by 30\%,50\%, and $100 \%$ plastic aggregate, respectively. This finding reveals that the addition of plastic aggregates in concrete increases the air content.

Similar results have been reported by others $[15,37,47]$. The irregular shape of the plastic aggregates may contribute to the higher air content in concrete. The immiscibility of natural sand and plastic fine aggregate could also be responsible for the increase in air content. Furthermore, the hydrophobic nature of polymers may cause air bubble formation on the surface of waste plastic aggregates. Therefore, some authors propose the use of air-reducing agents in such mixtures [15].

Also, plastic aggregates may influence the practical aspects of concrete placement. They can act as a spring when concrete is compacted using vibration. The typical flatter shape of plastic expands in order to relieve the internal stress induced by the compaction, and the expansion, in turn, creates increased air content within the concrete [46]. The shape of the plastic aggregates may need to be controlled to overcome the increase in air content. In this regard, new methods of pre-processing of plastic aggregates would be required instead of the conventional mechanical processing. Some chemicals can be used to treat the shape of the aggregates, which may improve the overall grading of the aggregates. Modifying the shape of PET particles was proposed by Choi et al. [30]. The modification was achieved by coating PET particles (5 to $15 \mathrm{~mm}$ ) with fine river sand (10 to $20 \%$ of weight) in a chamber where the applied temperature and mixing rotation were about $250 \pm 30^{\circ} \mathrm{C}$ and 30 to $50 \mathrm{rpm}$. After cooling, a sieve size of $0.15 \mathrm{~mm}$ was used to separate the finer size of manufactured waste PET particles; the final size and shape are shown in Figure 4c. This procedure increased the density of waste plastic aggregates by about $47 \%$, thereby reducing the possible segregation of the mix ingredients.

\subsection{Fresh and Dry Density}

The density of concrete depends on the specific gravity of the mix compositions and compactness of concrete. Since waste recycled plastics typically have lower density compared to natural aggregates, it is expected that both the fresh and the dry density will decrease in proportion to the substitution level $[22,26,41,48,49]$. Studies have shown that as the percentages of recycled plastic waste increased, the fresh density of concrete reduced, as shown in Figure $5[28,50,51]$. This loss in density is found to be greater when progressively bigger and flakier particles are incorporated [41]. For concrete produced from recycled E-plastics (collected from electronic waste) as coarse aggregates, the fresh density of the concrete gradually reduced with an increase in the e-plastic content [52]. E-plastic aggregates replaced the natural coarse aggregates up to a maximum of $50 \%$, and about $220 \%$ lower density was reported when compared with the control mix.

Similarly, where natural aggregates were substituted with recycled plastic contents at $25 \%, 50 \%$, $75 \%$, and $100 \%$, the 28 -day dry of concrete density was reduced by $7 \%, 20.5 \%, 33.5 \%$, and $42.3 \%$, respectively when compared to the control [24]. This trend of lower dry density was also reported 
by [50]. About $57 \%$ reduction in density is reported for concrete when the fine plastic aggregates replaced $50 \%$ of natural sand [50]. The same trend was found in lightweight self-compacting concrete, with some aggregate substituted with waste plastics (Figure 6). The lower density of concrete with plastic aggregates can be explained by the lower specific gravity (range of 0.52 to 1.01) of waste plastic, as reported in $[23,32,53]$.

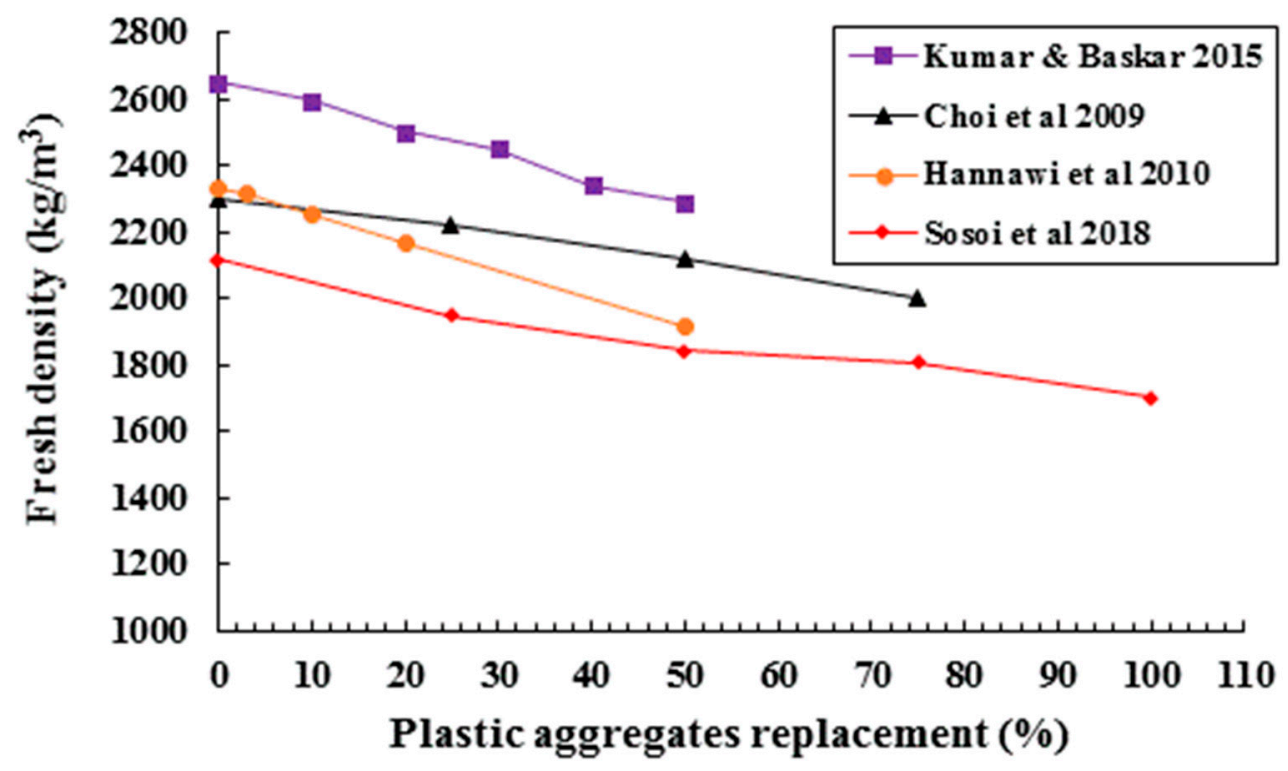

Figure 5. Fresh density of concrete with plastic aggregates [28,30,51,52].

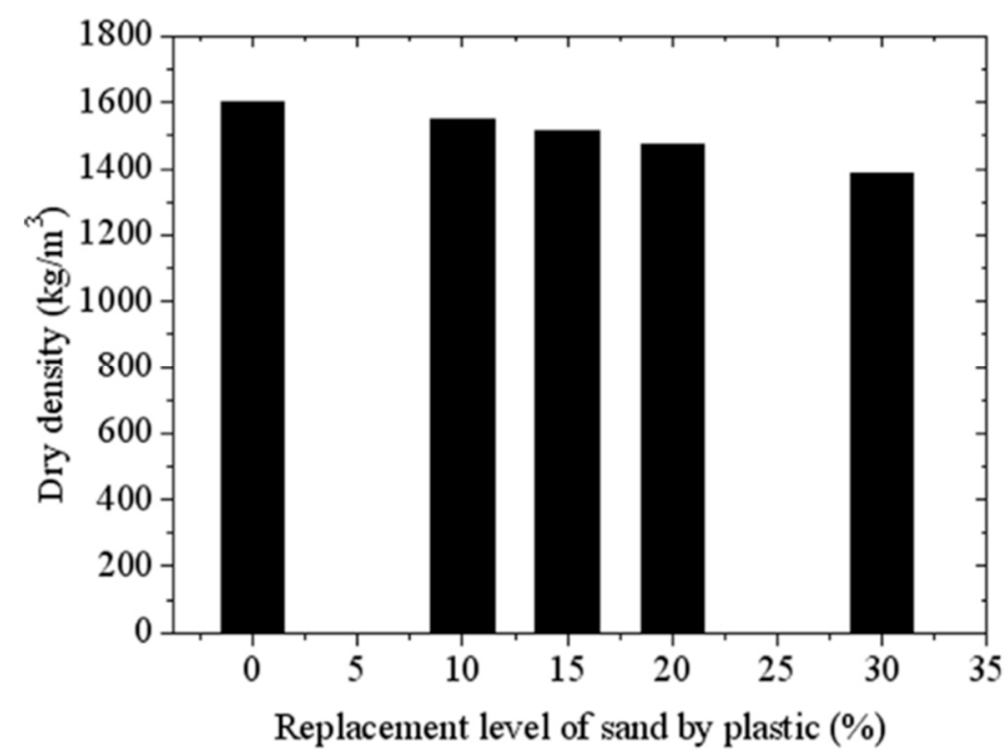

Figure 6. Variation of dry density of lightweight self-compacting concrete with increasing waste plastic content [54].

\section{Mechanical Properties}

In cementitious materials, mechanical properties are the most important parameter defining its suitability for practical application. This section aims to summarize the mechanical properties of concrete with recycled waste plastic reported in the literature. 


\subsection{Compressive Strength}

The compressive strength of concrete with various percentages ( $5 \%$ minimum to maximum $100 \%$ ) of recycled waste plastic as both coarse and fine aggregates was investigated by various researchers as shown in Figure 7. Most authors reported a gradual decrease in the compressive strength with increasing waste plastic percentages [27,55-59]. Kou et al. [60] replaced up to $50 \%$ of sand by polyvinyl chloride (PVC) granules in the concrete mixes. At 28 days, about 50\% lower compressive strength was found when compared with the reference concrete. In the same concrete mix, at $30 \%$ replacement of sand, the reduction of strength was about $25 \%$. It should be noted that for the processing of the PVC granules, PVC scrapers were crushed to a size between $1.18 \mathrm{~mm}$ and $4.75 \mathrm{~mm}$. The shape of the PVC granules was angular. Specific dosages of superplasticizer were used to adjust the slump values within the range of $160-180 \mathrm{~mm}$.

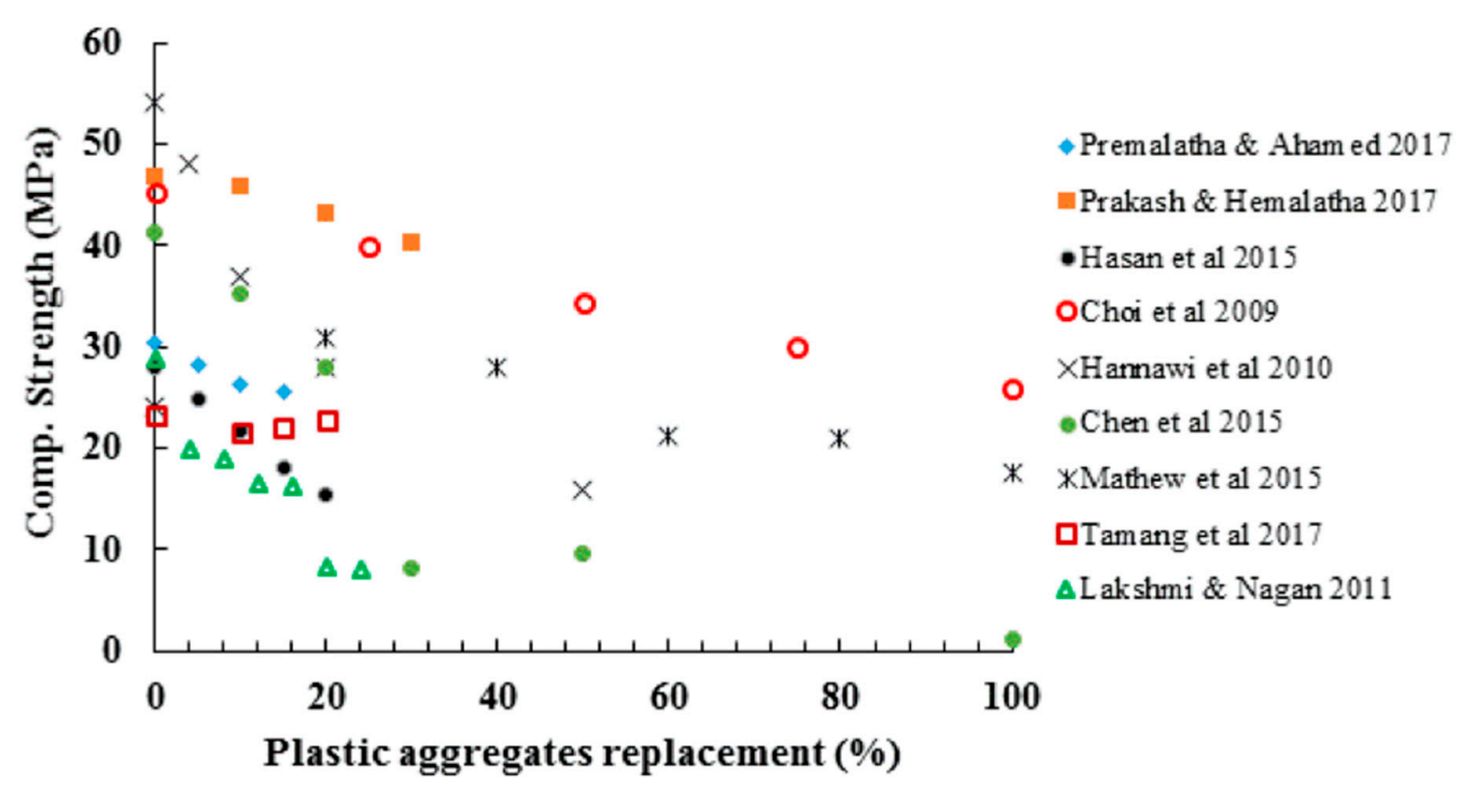

Figure 7. 28-day compressive strength of concrete with recycled plastic aggregates [27,28,30,46,55-59].

The reduction of compressive strength was also found to be present at different test ages, up to 56 days [26,30]. It was also found to hold for different $\mathrm{w} / \mathrm{c}$ ratios, both for mortar and concrete [30] (Figure 8). Three different mechanisms influencing the decrease in compressive strength have been proposed $[15,22,61]$. They are (1) waste plastic aggregates have a lower strength and a lower stiffness compared to natural aggregates and can, therefore, act as stress concentration zones favoring damage propagation; (2) low strength of the interfacial transition zone between the waste plastic aggregate and cement paste (see Figure 9); (3) increased air content in the mix. Islam et al. [22] further added that, since plastic aggregates have almost no water absorption capacity, water will accumulate in the ITZ, causing it to be more porous. This extra porosity will cause a reduction in compressive strength. Typically, the smooth surface of most plastic aggregates causes a weak bond between the cement matrix and aggregates, causing the lower strength of concrete. However, this issue can be reduced by increasing the roughness of the surface of aggregates.

Some authors, however, reported a different trend. For example, Yang et al. [54] found an increase in compressive strength of lightweight SCC for low replacement levels $(<20 \%)$. Higher replacement still led to a decrease in compressive strength. They attributed such behavior to the source of plastics used in the study: it was obtained from industrial plastic floorboards or car bumpers and could have been harder than plastics used in other studies. Similar results were reported by Azhdarpour et al. [53], who found an increased compressive strength for replacement levels up to $10 \%$ of PET plastics. They attributed this to the presence of plastic particles at the starting points of failure. According to these authors, at these points, in dealing with flexible plastic fragments, a portion of the shear stress 
is converted to tensile stress, which is consumed to overcome the tensile strength of the plastic segments. Because of their elongated sheet-shaped structure, plastic fragments tolerate part of the stress before their separation. However, increasing the amount of plastic decreased the compressive strength. This behavior is unusual and unexpected; however, similar cases have been reported in the literature. For example, Aguayo et al. [62] studied how the replacement of aggregate with compliant inclusions (in their case, microcapsules containing phase change materials) influences the mechanical properties of concrete. Similar to Azhdarpour et al. [53], they observed that at low substitution levels, the replacement of hard sand with soft inclusions led to an increase in the compressive strength. With the aid of numerical simulations, they attributed such behavior to stress redistribution between soft and hard inclusions (i.e., sand) at moderate replacement levels, which leads to stress transfer to strong (sand) inclusions and delays failure. At higher addition levels of compliant inclusions, stresses increased at the inclusion/paste interface, leading to a decrease in strength. It is possible that similar mechanisms occur in composites with waste plastics as (partial) aggregate replacement.

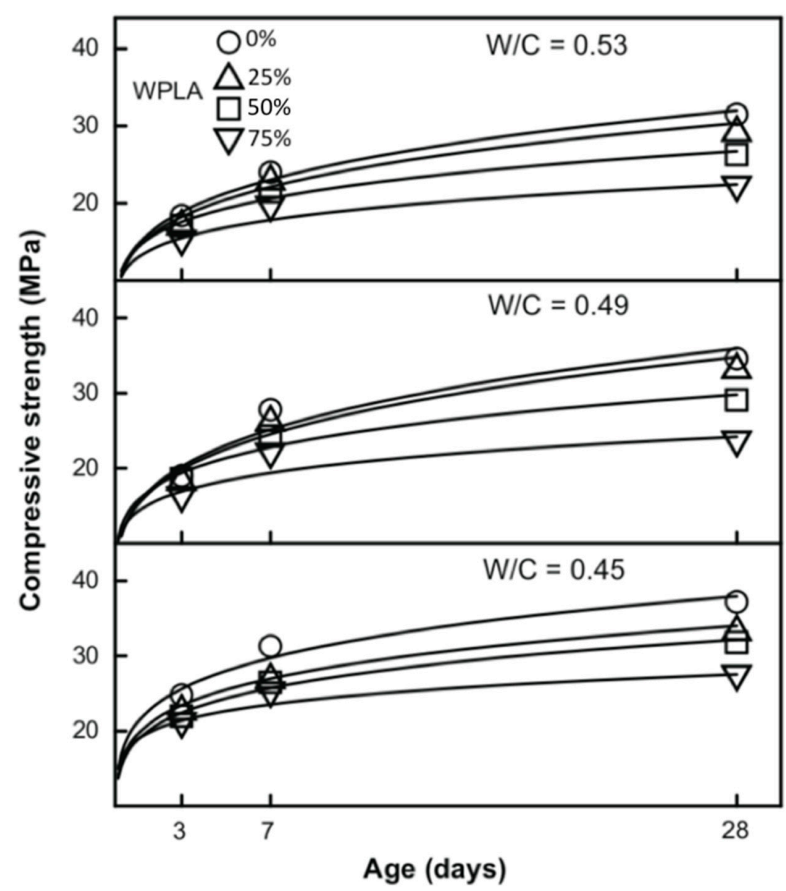

Figure 8. Development of compressive strength in time for various $\mathrm{w} / \mathrm{c}$ ratios and waste plastic replacement levels [30].

(a)

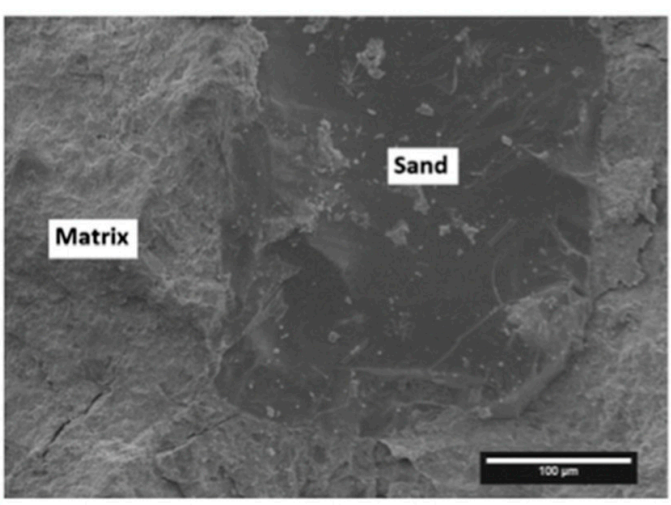

(b)

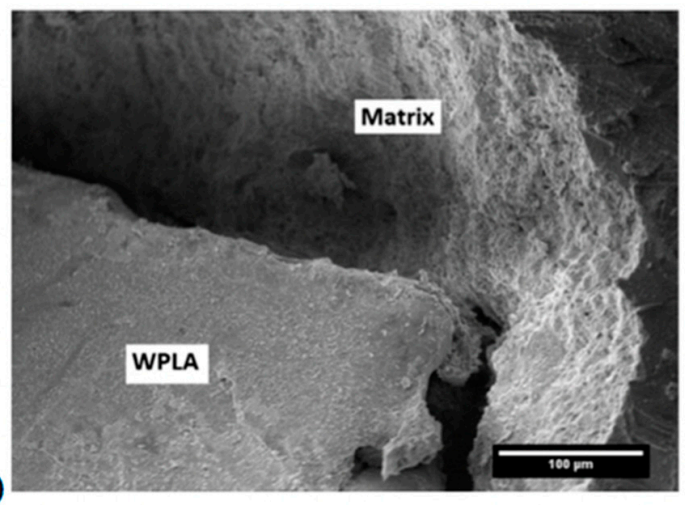

Figure 9. Scanning electron micrographs showing the bond between aggregate and cement paste: (a) natural aggregate; (b) waste plastic aggregate (WPLA) [49]. 
Similar findings were reported when waste plastic was used as fiber in concrete. The compressive strength of concrete with metalized plastic waste (MPW) fibers reduced as the percentages of fiber content and length increased. Concrete mixes with $5 \mathrm{~mm}$ fiber length and $0.5 \%, 1 \%, 1.5 \%$, and $2 \%$ content of MPW fiber, recorded about $5 \%, 10 \%, 15 \%$, and $21 \%$ lower compressive strength, respectively. For the same amount of fiber content but with $10 \mathrm{~mm}$ and $15 \mathrm{~mm}$ fiber lengths, lower strength by $8 \%, 13 \%, 18 \%, 26 \%$ and $8 \%, 15 \%, 21 \%, 28 \%$, respectively, was reported [20]. The reason for the lower compressive strength of concrete was discussed by Mohammadhosseini et al. [63], where similar methodologies were followed for concrete with MPW fibers up to $1.25 \%$. The conclusion of the study revealed that the addition of fibers increases the number of air voids in the matrix, which leads to lower compressive strength. Also, as discussed in earlier sections, the untreated surfaces of plastic fibers do not bond well with the cement matrix. Thus, a weaker interfacial zone is formed between the binders and plastic fiber, which ultimately leads to the lower strength of the concrete.

Concerning the bond between the plastics and cement, since no chemical bond exists between plastic and cement materials, Naik et al. [64] suggested treating the recycled plastics with different types of chemicals (oxidizing chemicals) to enhance the bonding characteristics. It is believed that the reaction of plastics and oxidizing chemicals produce some chemical species on the surface of the polymer, which could ultimately participate in the cementitious reaction. Such a reaction will produce cement paste like the product and improve concrete properties due to the presence of polymeric substances [64]. Therefore, for the experiment, fine plastic samples (1.18 $\mathrm{mm}$ passing and retained on $4.75 \mathrm{~mm})$ were treated by soaking them in water, bleach $(5 \% \mathrm{HOCl})$, and bleach plus $\mathrm{NaOH}(5 \%$ $\mathrm{HOC} 1$ and $4 \% \mathrm{NaOH})$. Although the compressive strength was reduced due to the use of waste plastic aggregates, the reduction was lower for aggregates subjected to bleach or bleach plus $\mathrm{NaOH}$-treated plastic compared to plastic aggregates treated with water [64]. Therefore, chemical pretreatments of plastic aggregates may offer a way to (partially) offset the drop in compressive strength of these concretes. Other pretreatments (e.g., physical pretreatment or coating) may present an alternative, but more research is needed for their optimization [65].

\subsection{Elastic Modulus}

Similar to the findings on the compressive strength of concrete containing plastic, the elastic modulus of concrete reduced linearly as the percentages of plastic aggregates replacement increased in the mix $[28,53]$. The low elastic modulus of plastic is the main cause of the lower elastic modulus of concrete [26]. Such behavior is expected according to the theory of composite materials, which states that the elastic properties of a composite depend (mainly) on the elastic properties of the constituent materials and their relative amounts [66]. Furthermore, it has been found that the drop in elastic modulus is lower than the drop in compressive strength $[15,61]$ (e.g., Figure 10). Similar findings were reported in the literature for other types of soft inclusions (e.g., functional microcapsules $[67,68]$ or expanded polystyrene beads [69]). This was attributed to the fact that failure is governed by stress concentrations around such inclusions, while elastic properties are governed by the constituents and their (relative) proportions [70,71]. Note that the horizontal axis of Figure 10 denotes the percentage of aggregate replacement in different concrete grade mixes. 

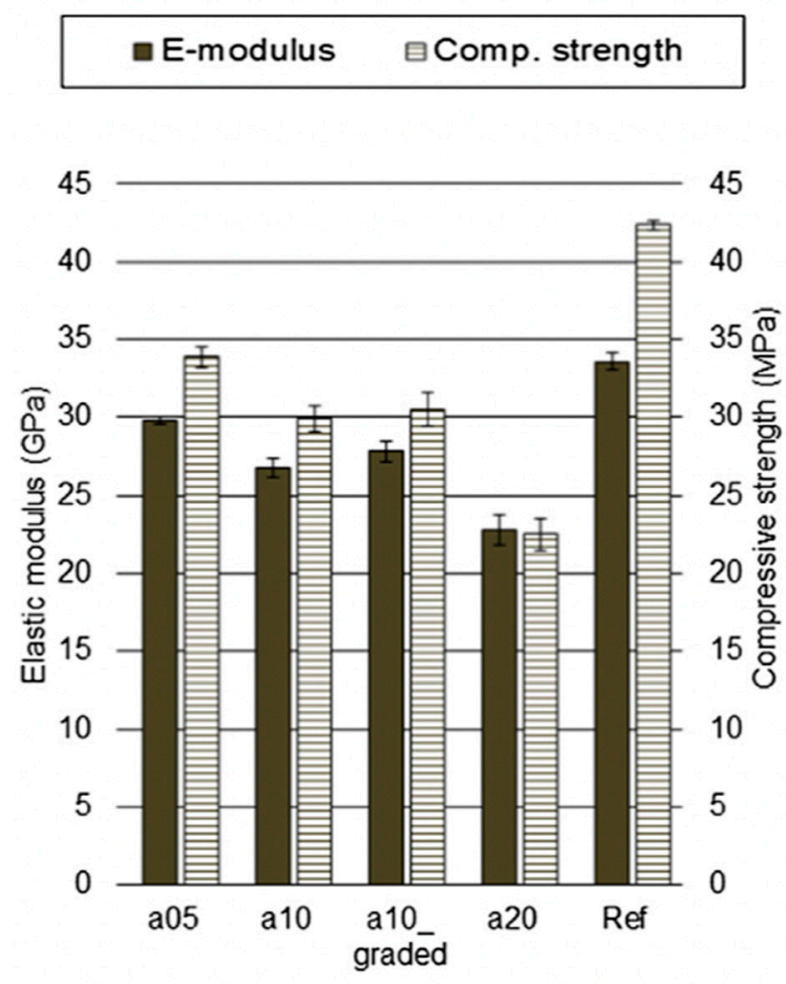

Figure 10. Measured elastic moduli and compressive strength for different percentages of waste plastic aggregate in concrete (on the horizontal axis, the number signifies the percentage of waste plastic aggregate replacement, and the underscore a different aggregate grading) [15].

In addition to changing the elastic modulus, one study [54] reported that the addition of $15 \%$ of waste plastic aggregate significantly alters the Poisson's ratio of the concrete. Compared to the reference concrete (with a Poisson's ratio of 0.195), concrete containing waste plastic aggregate had a significantly higher Poisson's ratio (0.25). Additional studies are needed to reveal the reasons for such behavior.

\subsection{Tensile, Flexural, and Fracture Properties}

It is expected that the (partial) replacement of natural aggregates with waste plastic aggregates will affect the tensile, flexural, and fracture properties of concrete. The majority of studies report a gradual decrease of flexural/splitting tensile strength with increasing percentages of waste plastic aggregates. For example, Akçaözoğlu et al. [72] compared the flexural and tensile strengths of mortar containing only PET as the fine aggregate with PET and sand mixed mortar. The strength of mortars with a combination of PET and sand aggregates was higher than the mortars containing only PET aggregates [72]. In a different study, a gradual reduction in the flexural strength of PVC mixed concrete was reported as the percentages of PVC content increased from $2.5 \%$ to $20 \%$ [73]. At 120 days of testing, about $19 \%$ and $96 \%$ lower flexural strength were noticed for concrete with $2.5 \%$ and $20 \%$ PVC, respectively, when compared with the control mix. The study further revealed that for concrete samples containing $20 \%$ of PVC, the surface quality was poor [73]. The concrete sample surface crumbled with higher content of PVC as a result of poor strength. Other studies (e.g., [26,48,61,74]) also reported a drop in flexural/bending strength (Figure 11). As shown in Figure 11, the ultimate splitting and flexural strength of concrete gradually decreased as the replacement level of the PVC powder increased in concrete. This was mostly attributed to the same factors causing a decrease in compressive strength with waste aggregate plastic addition, mainly the weak bond between the aggregates and the cement matrix. After reaching the ultimate strength, most plastic particles in the concrete matrix do not fail but are debonded from the cement paste, which is additional evidence of the poor bond (see Figure 12). 


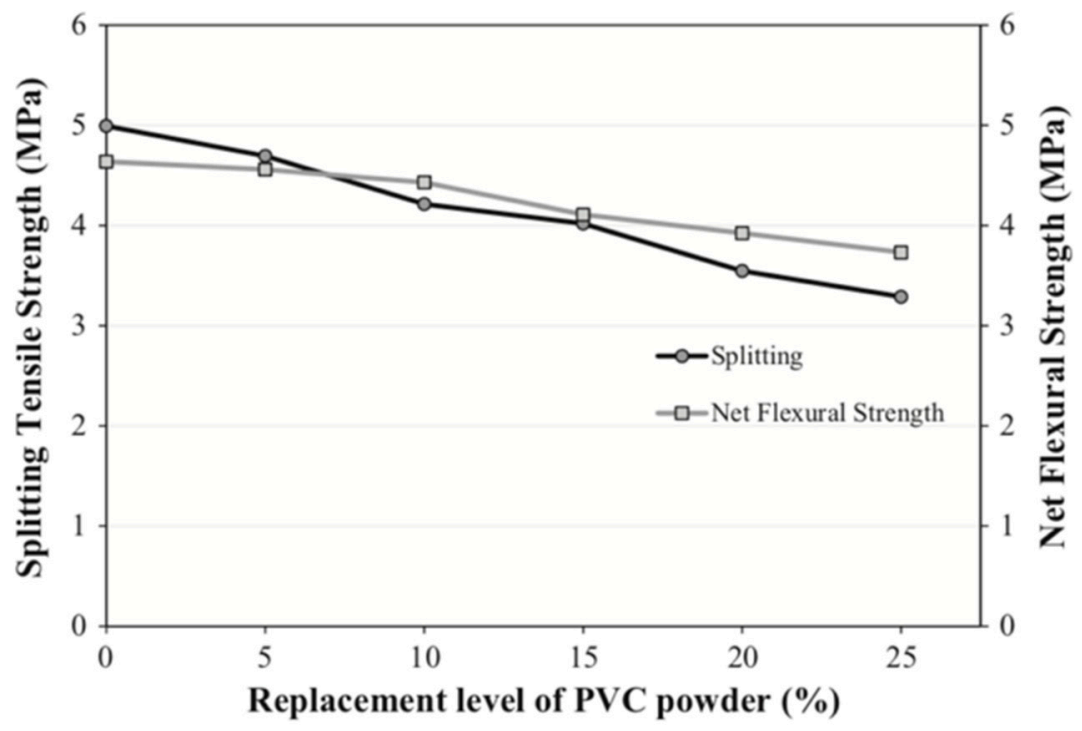

Figure 11. Variation of splitting and net flexural strength according to the content of PVC powder (net flexural strength stands for ultimate flexural strength) [61].

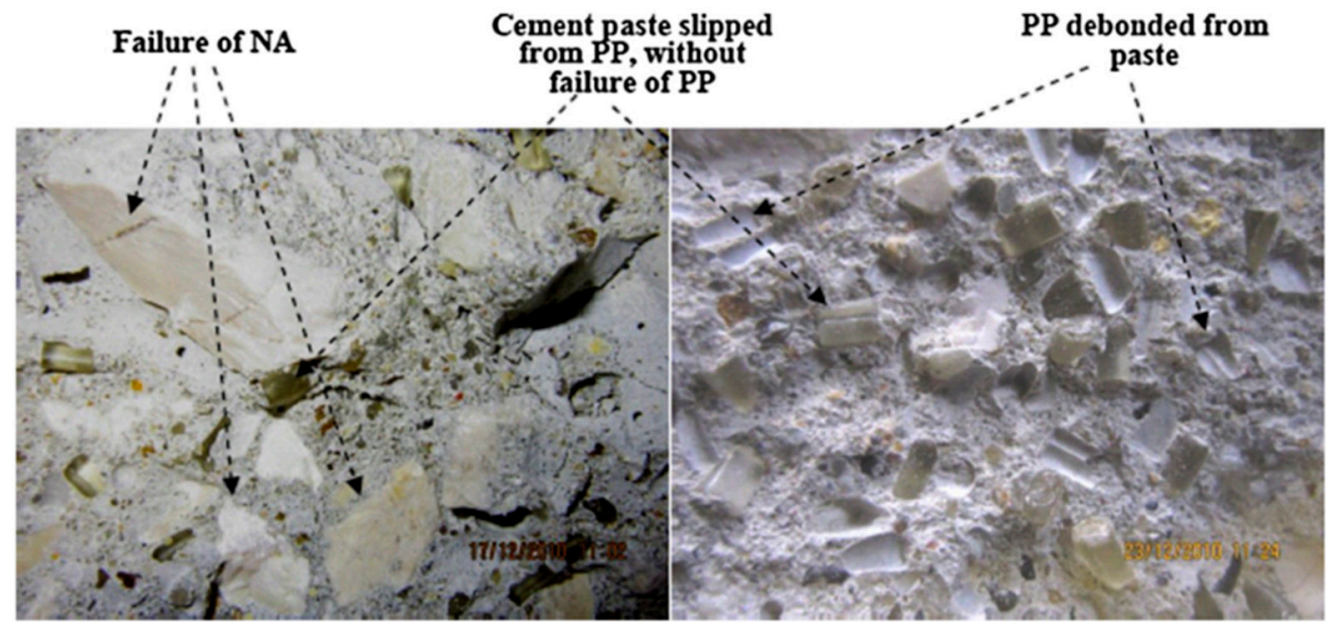

Figure 12. Concrete specimens containing plastic particles (PP) after failure in the tensile splitting strength test (NA-normal aggregate) [43].

However, several authors have reported that a moderate level of waste plastic aggregate can increase the flexural/splitting tensile strength of concrete. Mohammadhosseini et al. [63] used different percentages $(0.25,0.5,0.75,1.0$, and 1.25) of MPW fibers in concrete and their performance under flexural and direct tensile strength tests was investigated. Mixes containing fiber percentage of $0.5 \%$ showed the highest flexural and tensile strengths. With a fiber content of $1.25 \%$, there was no noticeable difference in the strengths compared to the reference (i.e., without the inclusion of fibers). Yang et al. [54] observed that moderate replacement of natural aggregates with waste recycled plastics could increase the flexural and splitting tensile strength of concrete (up to $15 \%$ and $20 \%$ replacement for splitting and flexural strength, respectively). Similar findings were reported by others $[34,53,75]$. Replacing more than $20 \%$ of natural aggregate with waste plastic particles, however, still led to a decrease in flexural and splitting tensile strength.

Although in most cases the splitting strength of concrete reduces as the plastic aggregate content increases, the reduction in the splitting strength can be lowered as the water-cement ratio of the concrete mix reduces [76]. As previously observed, poor bonding between aggregates and cement paste is responsible for the lower strength. Therefore, in achieving better performance of plastics in 
concrete, surface treatment of plastics could be of use, which may improve the bond behavior between the plastic and cement paste interface.

It is worth mentioning that the addition of plastic aggregates tends to increase the ductility of concrete. However, the ductility of plastic concrete is related to the type of plastics used. Therefore, depending on the design requirement, proper plastic types must be used in concrete for better performance. A study by Hannawi et al. [74] showed that the bending capacity increases slightly for low replacement levels, but then more significantly when the plastic aggregate content reaches $50 \%$. The ductility was found to increase significantly even for low levels of aggregate replacement. They attributed this to the fact that the plastic/matrix interface acts as an obstacle to microcrack propagation. Since this interface is weak, it leaves a vacuum that constitutes an obstacle to crack propagation. Finally, the plastic aggregates themselves prevent the propagation of microcracks and delay their coalescence. In other studies, it was suggested that a small fraction of the waste plastics has a shape similar to short fibers, and is able to bridge the crack to a certain extent, providing the material with some post-peak toughening [48]. The lower elastic load ratio of concrete with 50\% PET content can be explained by the availability of less cement paste on the higher surface area of $50 \%$ PET content than others.

Fracture parameters of concrete also tend to be altered by the waste plastic addition. Fracture energy (Gf) is a useful parameter to characterize the post-peak behavior of concrete $[77,78]$. Gesoglu et al. [61] found that the fracture energy of concrete decreases with PVC powder percentage (Figure 13). They stated that the presence of weak PVC particles and increased air void content cause a decrease in the fracture energy of concrete. On the other hand, they also looked at the characteristic length of concrete $\left(l_{c h}\right)$, which is a measure of concrete brittleness [79]. A study [61] found that the characteristic length of concrete increases with increasing PVC powder replacement percentage (Figure 13), meaning that these concretes are more ductile (as also described above). This was attributed to the weak paste-plastic aggregate interface and non-homogeneous microstructure, which cause a reduction in brittleness. Nevertheless, the hardened properties of plastic aggregate concrete do not depend only on the percentages of plastic content in the mix; they are also influenced by the shape and size of plastic aggregates, as well as the concrete mix compositions. Further research is required to investigate these issues.

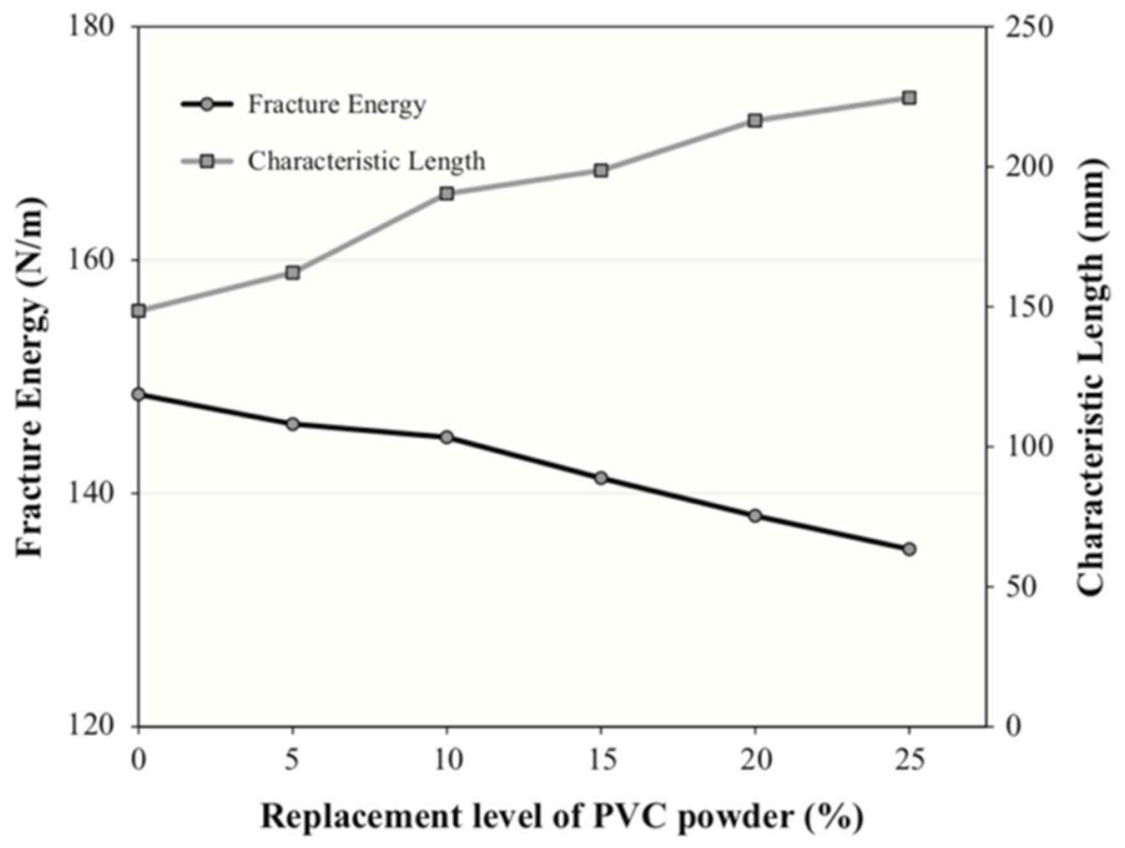

Figure 13. Variation of fracture energy and characteristic length according to the content of PVC powder [61]. 


\subsection{Ultrasonic Pulse Velocity}

An ultrasonic pulse velocity (UPV) is a non-destructive test to check the quality and uniformity of concrete. Concrete strength and durability are assessed by measuring the velocity of an ultrasonic pulse through the concrete specimen. UPV of good quality concrete should be in a range of 4100 and $4700 \mathrm{~m} / \mathrm{s}[80,81]$. Generally, pulse velocity is influenced by the material's density, moisture content, and elasticity [82]. Figure 14 shows the UPV performance of concrete specimens at different curing ages with different percentages of PET content. Lower UPV is found in concrete with increased PET content at an early age. However, the differences in the results were less significant at later ages [25]. Albano et al. [29] reported that the values of UPV of concrete with 10\% PET are more similar to the traditional concrete even at two different water-cement ratios (0.50 and 0.60). An accepted range of UPV with both fine and coarse plastic aggregates was also noticed in some studies $[83,84]$, and excellent behavior was reported for concrete with $15 \%$ plastic aggregates. Senhadji et al. [85] concluded that a maximum 50\% inclusion of PVC aggregates (maximum size up to $8 \mathrm{~mm}$ ) is acceptable for UPV since the concrete with 70\% PVC shows UPV value outside the accepted range, as suggested by [80]. Nevertheless, the UPV value reduces as the percentage of plastic aggregates content increases in concrete. The reduction in the UPV is a result of higher air void content in plastic waste concrete, which attenuates the propagation of UPV by acoustic impedance. Typically, when a pulse passes through different materials, it is partially transmitted; therefore, the velocity decreases. Also, UPV depends on the volumetric concentration of different constituents, and when plastic aggregates are replaced for natural aggregates, the UPV decreases [85].

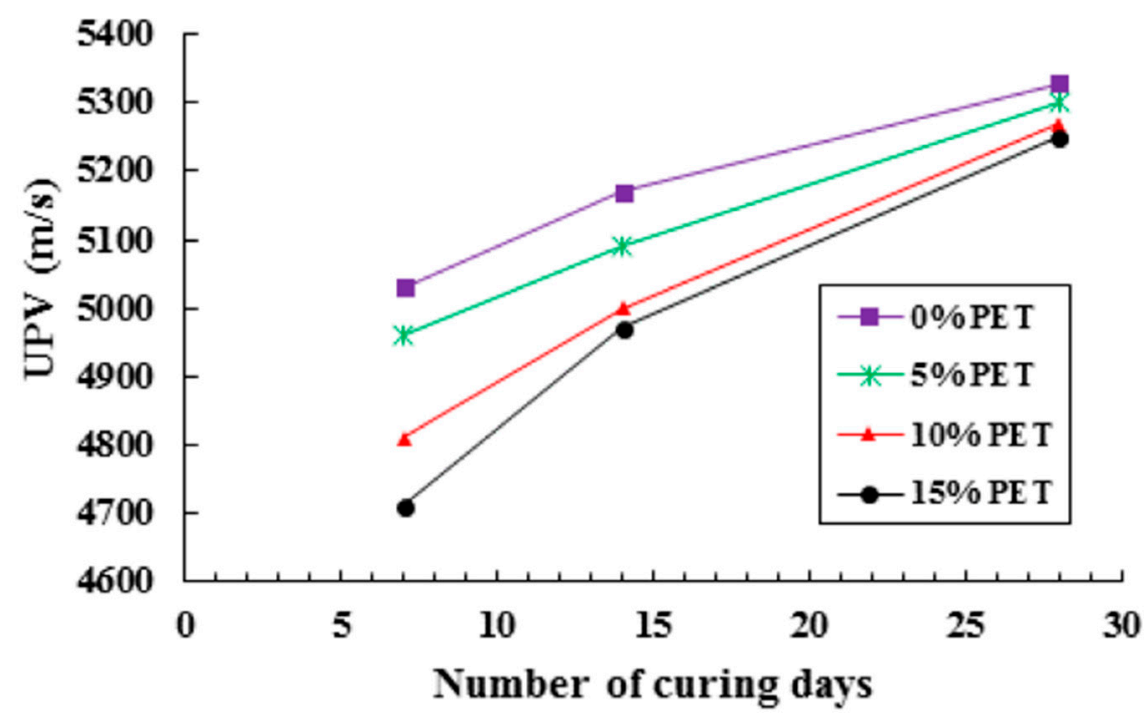

Figure 14. Ultrasonic pulse velocity (UPV) in concrete with different percentages of PET in the mix [25].

From the discussion above, it can be seen that the inclusion of waste plastic in concrete as aggregates and fiber negatively affects the mechanical properties. However, the rate of strength reduction is not directly related to the percentage replacement of plastic in concrete. Other parameters such as the type of plastic, size, and shape may be the factors contributing the most to the reduced concrete strength. Nevertheless, these issues are not appropriately highlighted by researchers. Instead, they have focused on the influence of the percentage of waste plastic replacement on various properties of concrete. This identifies a need for further research on recycled plastic in concrete.

Furthermore, the microstructure of concrete with waste plastic has also not been adequately studied. The lower strength of concrete is related to the bond strength between the plastic aggregates/fiber and binder matrix, which has also not been examined properly. The improvement of the surface quality of plastic aggregates can significantly improve the mechanical strength of concrete. Although some researchers have tried to improve the surface quality of plastic aggregates using 
oxidizing chemicals like sodium hypochlorite, the cost, health, and environmental issues have not been adequately addressed. Therefore, more research is required to identify oxidizing agents that are environmentally friendly and also economical. Also, for the same type and dosage of plastic aggregates, different researchers found different ultimate strengths. This can be explained by the fact that, even though the same plastic types were used, the mix compositions, size, shape, compaction factor of fresh materials, and curing conditions of samples were different from researcher to researcher. Though it can be concluded that the incorporation of plastic aggregates reduces the strength of concrete, the obtained strength of waste plastic concrete may still be sufficient for some structural and non-structural applications. Therefore, more research is required to classify the potential uses of certain percentages of plastic waste in concrete.

\section{Durability}

The durability of concrete relates to the permeability of fluids and gas, as they are responsible for the corrosion of steel in concrete. Therefore, the selection of proper concrete materials is critical for enhancing durability. There have been concerns about the recycling of waste materials in concrete due to the presence of possible contaminants. Existing research showed that recycled plastic aggregates do not have good durability like natural aggregates. However, some studies have shown that durability can be improved by mixing other special materials into the concrete or by altering the properties of the plastic. This section describes some of the durability tests that have been conducted on concrete with recycled waste plastic.

\subsection{Shrinkage}

Restrained shrinkage may lead to cracking of concrete even before the application of external loads. When it comes to the influence of waste recycled plastic aggregates on the shrinkage of concrete, conflicting findings have been reported in the literature. Some authors have reported that free and drying shrinkage increase with an increasing level of waste recycled plastics in the mix. This is expected behavior as shrinkage depends on two material parameters: shrinkage of the cement paste and the aggregate content and stiffness. Since aggregates do not shrink, they present internal restraints to the shrinkage. Therefore, stiffer aggregates essentially mean lower shrinkage. As recycled waste plastic is typically more compliant than natural aggregates, it is expected that its use will lead to an increase in shrinkage. Akçaözoğlu et al. [72] reported that when PET aggregates replaced 100\% fine aggregate, an increase of $56 \%$ in the drying shrinkage was recorded over and above the concrete containing $50 \%$ PET aggregates. In another study by [86], at 28 days, an increase of $20 \%$ in the drying shrinkage was measured in concrete with $20 \%$ PET content compared to the reference concrete. Hannawi et al. [74] also observed higher free shrinkage with increasing PET aggregate content.

Furthermore, the long-term shrinkage behavior of concrete containing fine PET aggregates was investigated and reported by Frigione [31]. Less than 3\% higher shrinkage value was found in concrete specimens with 5\% PET aggregates. The higher shrinkage value of plastic aggregates concrete can be explained by the lower elastic modulus of plastic aggregates than the conventional aggregates. Such behavior was also reported for other compliant inclusions, such as modified, expanded polystyrene aggregate [87].

Some authors have reported that the addition of recycled waste plastic aggregates decreases the drying shrinkage of concrete. Silva et al. [41] reported a decrease in drying shrinkage with the addition of waste plastic aggregates. They attributed this to the impervious nature of waste plastic aggregates, which reduced the amount of water absorbed by the aggregates, thereby leaving more free water for cement hydration. Since drying shrinkage is caused by the capillary tensile force induced as a result of water loss in concrete, such behavior will consequently result in reduced drying shrinkage.

It is also interesting to note that, although an increase in free shrinkage as a result of the recycled waste plastic addition is commonly reported, it seems that this addition at the same time causes a decrease in restrained shrinkage cracking. Hannawi et al. [74] reported that the plastic aggregate 
incorporation reduces the sensitivity of mortars to shrinkage cracking-it delays the appearance of cracks and reduces their width. Soroushian et al. [88] reported similar findings. This was attributed to the fact that plastic aggregates, on the one hand, improve the deformation capacity before crack localization. On the other hand, PET flake-shaped particles acted as fibers and restrained the crack opening after cracking.

\subsection{Water Absorption and Porosity}

Water absorption indicates the degree of porosity of materials by determining the percentages of water absorbed under a specific condition [89], and it is proportional to the square root of time. Measurements of the porosity of hardened cement paste can be determined by water saturation, where water molecules can enter spaces in the microstructure [90].

Water absorption and porosity tests were performed by various researchers on concrete samples with plastic aggregates to evaluate the capability of this type of concrete to avoid steel corrosion $[23,28,50,73]$. As shown in Figure 15, water absorption increases as the percentage of plastic aggregates content increases. Water absorption in concrete increased exponentially as the percentages of recycled e-plastic content increased [23]. Almost 100\% higher water absorption was noticed in concrete with $15 \%$ coarse e-plastic compared to the reference concrete. Coppola et al. [50] replaced natural sand with recycled plastic aggregates at 10\%, 25\%, and 50\% in producing lightweight foam concrete. They found almost the same amount of water absorption with $10 \%$ sand replacement by plastic aggregates. However, this trend was not valid for higher amounts of plastic in concrete. About $117 \%$ higher water absorption was found in concrete for $50 \%$ sand replacement by plastic aggregates. The higher amount of porosity induced by the plastic aggregates caused this drastic change in the water absorption in concrete. This was also reported by Ruiz-Herrero et al. [73]. About $200 \%$ and $140 \%$ higher porosity were found in concrete at 28 days with $20 \%$ inclusion of polyethylene (PE) and PVC plastic aggregates [73].

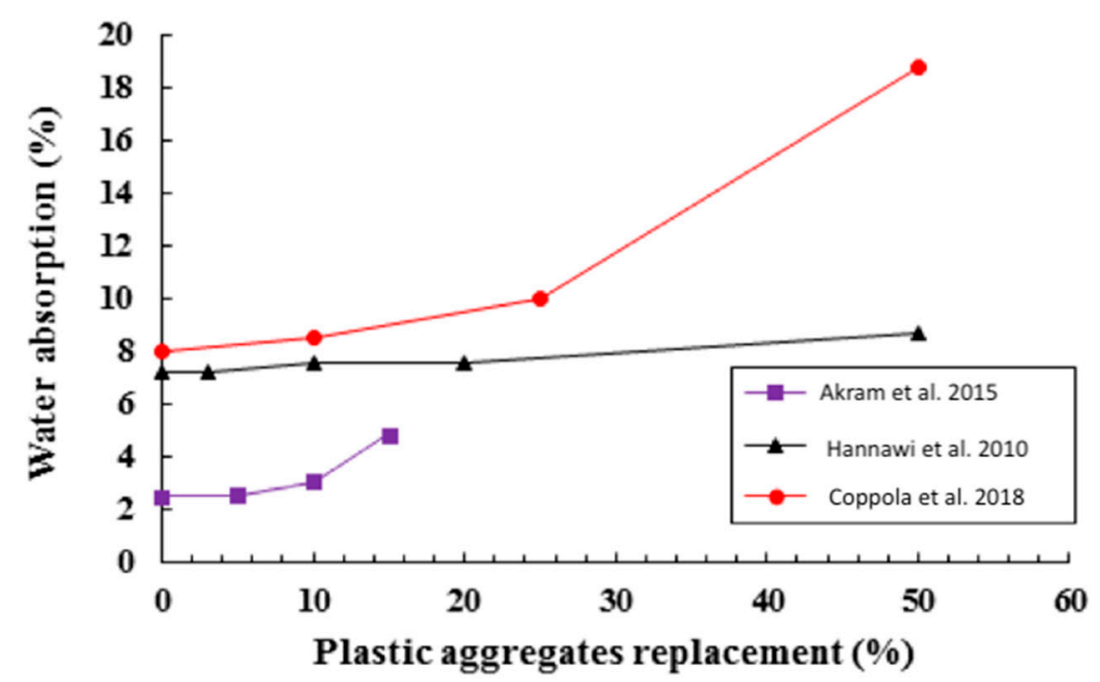

Figure 15. Water absorption capacity of concrete with plastic aggregates.

On the other hand, Jacob-Vaillancourt and Sorelli [15] did not find a direct correlation between the amount of waste plastic aggregate and water absorption. In their study, unexpectedly, the mix with the highest air-void content was characterized by the lowest water absorption. This was attributed to the presence of admixtures (air-reducing surfactant) in some of the mixtures-it could have possibly had the effect of reducing the hydrophobicity of waste plastic aggregate. 


\subsection{Resistance to Chloride Ingress}

Chloride ingress in concrete can cause depassivation of steel reinforcement and the start of reinforcement corrosion, ultimately resulting in the end of service life of a structure [91,92]. As rust has a larger volume compared to virgin steel, corrosion will cause cracking of the concrete cover, further reducing the ability of the cover to protect the steel $[93,94]$. Therefore, resistance to chloride ingress is one of the most important indicators for durability assessment of concrete. However, conflicting results have been reported regarding the resistance of concrete incorporating recycled waste plastics to chloride ingress.

A study by Alqahtani et al. [95] found that resistance to chloride ingress of concrete improves with the addition of plastic aggregates. The chloride ion permeability in lightweight concrete with $100 \%$ coarse plastic aggregates and with 0.5 and 0.6 water-cement ratios was $15 \%$ and $12 \%$ lower than the respective reference concrete [95]. Similar findings were reported by Kou et al. [60], who attributed this to the impervious nature of waste plastic aggregates, which present a physical obstacle to chloride ingress (Figure 16). It is worth mentioning that, according to the ASTM C1202, if in a rapid chloride permeability test (RCPT) of concrete the charge (in coulombs) passed 4000, the resistance to chloride ingress is considered low. Note that P0, P5 to P45 in Figure 16 represent the percentages $(0 \%, 5 \%$ to $45 \%$ ) of recycled plastic aggregate replacement in concrete.

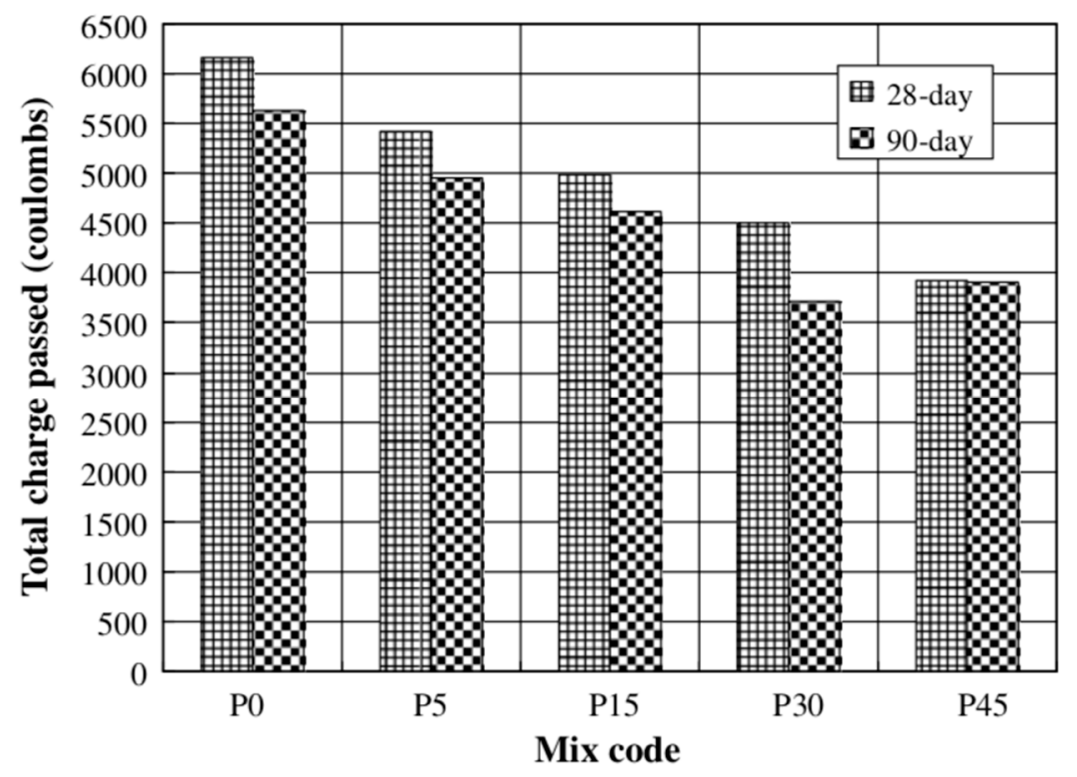

Figure 16. Resistance to chloride ingress of mixtures with increasing waste recycled plastic percentages measured by an RCPT (rapid chloride permeability test) [60]. Note that a higher charge passed indicates a lower resistance to chloride ingress.

On the other hand, some authors reported otherwise. Soroushian et al. [88] found only a small decrease in resistance to chloride penetration with the addition of waste recycled plastic aggregate. In their study, however, only small amounts of waste plastic aggregates were used-up to $5 \%$. Silva et al. [41] reported that the chloride migration coefficient increases with an increasing addition of waste recycled plastic aggregate. Furthermore, this trend was more pronounced in cases when curing was less optimal (Figure 17). No explanation was given for such behavior. This may be related to the increased void content, although this was not measured in their study. As discussed in Section 2.2, the addition of plastic aggregates in concrete may increase the air content. This typically causes higher chloride ingress in concrete. Chloride ingress in concrete is also related to the curing of concrete, which is sufficiently understood. The density of the microstructure of concrete depends on the curing condition, which may also play an important role in chloride penetration. 


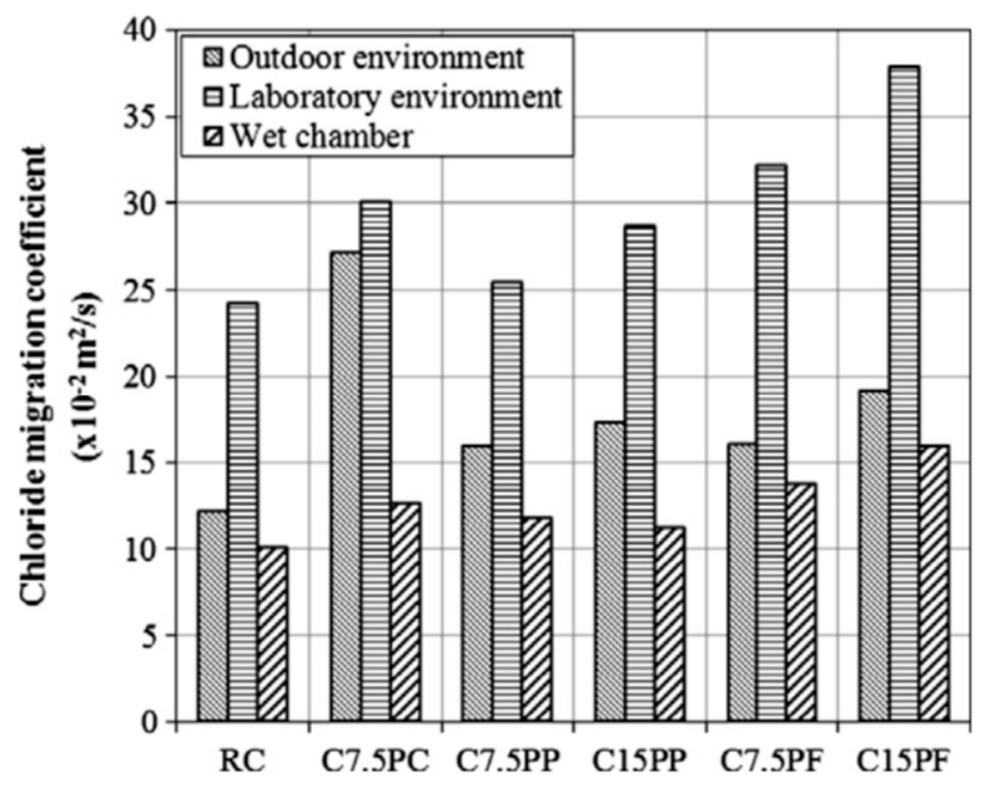

Figure 17. Chloride migration coefficient at 91 days of concrete mixes cured in different curing conditions [41] (RC-reference concrete. Numbers indicate different percentages of recycled waste plastics. PC - coarse plastic aggregate. PF-fine plastic aggregate. PP-pellet-shaped plastic aggregate).

\subsection{Other Durability Properties}

Other durability properties of concrete incorporating waste recycled plastics have been far less studied. Carbonation resistance of concrete is another parameter important for its service life [91] since carbonation of the concrete cover causes a reduction in $\mathrm{pH}$, which breaks down the protective layer around the reinforcement and causes corrosion [96]. Carbonation depth of concrete samples was found to be higher for a higher amount of PVC content [73]. Similar findings were reported by Silva et al. [41]. On the contrary, with porosity, the carbonation depth of concrete was higher for PVC than PE aggregates. At 28 days, more than $930 \%(9.3 \mathrm{~mm})$ and $650 \%(7.5 \mathrm{~mm})$ higher carbonation depths were noticed in concrete with PVC and PE aggregates than in the reference concrete, where a maximum carbonation depth of $1 \mathrm{~mm}$ was observed.

In a study by Soroushian et al. [88], the scaling resistance of concrete containing recycled waste plastics was tested. Low volume fractions $(2 \%)$ of recycled waste plastics did not change the scaling resistance of concrete. However, when more than $5 \%$ recycled waste plastic aggregate was used, higher scaling was measured. This was attributed to the fact that plastic particles, which are impermeable, tend to block bleeding water from reaching the surface. This causes cavities to form underneath plastic particles close to the surface, where ice can form to press plastic particles out of the surface.

The thermal conductivity of concrete is found to be significantly affected by the replacement of natural aggregates with waste plastic aggregates. Several studies have reported a decrease in the thermal conductivity of concretes with waste plastic aggregate addition [15,48,49] (Figure 18). In general, it was found that the thermal conductivity was proportional to the dry density [15]. Two main reasons were stated for the decrease in thermal conductivity: (1) waste plastic aggregates have approximately 5 times lower thermal conductivity compared to silica sand $(0.28-0.3 \mathrm{~W} / \mathrm{mK}$ and 1.3-1.4 W/mK, respectively), so the composite conductivity is decreased [48]; (2) the inclusion of waste plastic aggregates in general causes an increase in air void content, which also decreases the thermal conductivity [15]. Concrete incorporating waste recycled aggregates has, therefore, significantly improved insulating properties compared to concrete containing a natural aggregate. 


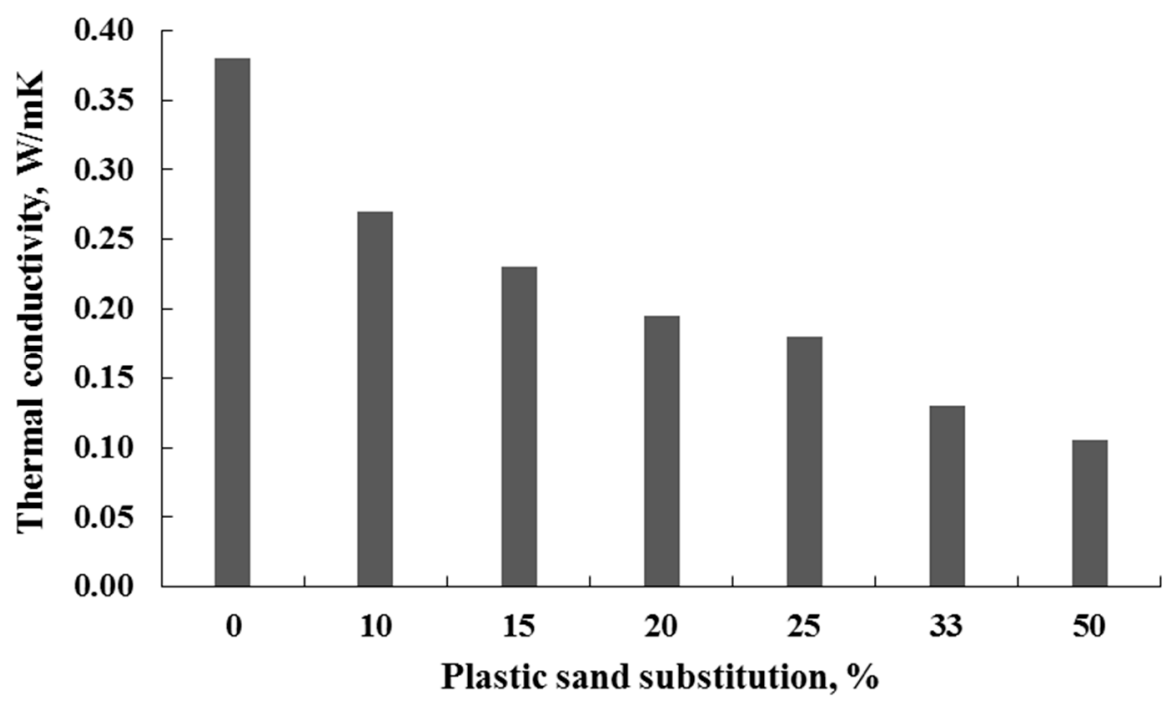

Figure 18. Thermal conductivity $(\lambda)$ measured at $\mathrm{Tm}=20^{\circ} \mathrm{C}$ and $\Delta \mathrm{T}=20^{\circ} \mathrm{C}$ [48].

The resistance of concrete-containing recycled waste plastic aggregate to high temperatures is also a concern. The residual compressive strength of concrete with different percentages of PET (as both fine and coarse aggregates) at different elevated temperatures was investigated by Saxena et al. [97]. Strength was gradually reduced as the percentages of PET content and temperatures increased. Concrete with $20 \%$ fine PET content, maximum $80 \%, 89 \%$, and $88 \%$ lower strength was found at an elevated temperature of $30{ }^{\circ} \mathrm{C}, 300{ }^{\circ} \mathrm{C}$, and $600{ }^{\circ} \mathrm{C}$, respectively. For a coarse PET, a maximum of $74 \%, 74 \%$, and $88 \%$ lower strength was reported. The reason for the lower strength is the porous structure of concrete with PET, which led to an imbalanced thermal gradient, causing the formation of cracks in the matrix. Also, the thermal degradation of PET may lead to split between the matrix, causing early cracking and thus lowering the strength.

\section{Concluding Remarks}

An up-to-date, comprehensive review of existing research output on the performance of recycled waste plastic in concrete has been undertaken. The effects of recycled waste plastics when used as fine and coarse aggregates, and fiber on the fresh, mechanical, and durability properties of concrete were reported. The intrinsic non-reactive behavior of plastic aggregates reduces the performance of concrete under both mechanical and durability tests. Increased air content and weak bonding between the plastic aggregate and natural aggregate have been adjudged the main causes of the reduced performance of recycled waste plastic concrete. The shape, size, and surface treatment applied to the plastic aggregate are also important for the performance of plastic aggregate concrete. One way to improve the performance of plastic in concrete is surface treatment. Chemical surface treatments such as common household bleach (sodium hypochlorite) with caustic soda (sodium hydroxide) were used by some researchers and led to significant improvements. It is concluded that when plastic was subjected to the chemical solution and dried, compounds originally dissolved precipitated on the surface of the plastic, forming crystals. These crystals dissolved in the water of concrete mix and decomposed in the high $\mathrm{pH}$ environment of the cement, forming oxygen [98].

The use of recycled plastic aggregates in civil engineering applications, such as pavement and infrastructure, can be an alternative to disposing of them in landfill sites. Recycled plastic aggregates can also be used for producing concrete bricks (for general applications), blocks (for river bank protection), façade elements, non-structural concrete panels, and temporary shelters. For structural concrete applications, structures with lower imposed loads and where the durability is less important, a certain amount of plastic aggregates may be used in concrete. Plastic fibers can be used in concrete to control cracks, shrinkage, and creep rather than using expensive synthetic or steel fibers. This will 
reduce not only the dependence on the natural aggregates, but possibly also the cost of concrete. From an environmental point of view, recycling of plastic waste can be beneficial to humans and marine life. The release of toxic chemicals from plastics may also be harmful to the land and water. However, these issues are not within the scope of this study as the focus of this paper is on the engineering properties of plastic aggregates in concrete. Through the literature search, it is postulated that up to $20 \%$ of plastic aggregates in concrete may be acceptable without compromising its engineering properties. Also, it can be hypothesized that the higher air content and poor bond capacity of plastic aggregates in concrete are the dominant factors of lower strength. In this regard, future research is required to improve these factors. Altering the shape, size, and surface of plastic aggregates can also play an important role in improving the concrete properties. The authors also believe there is a need for guidelines on the proper use of this material. Guidelines for plastic aggregate use in concrete that define the optimum content, acceptable size and shape, types of structures, etc. are also essential for reliable design and construction. Of course, standards are typically developed over several years, once sufficient, reliable data and sound understanding have been developed. Thus, the long-term performance of plastic aggregates in concrete, and their impact on both the environment and service life, are recommended to be further explored.

The following conclusions can be drawn based on the presented literature review:

- Workability increases as the content of coarse recycled waste plastic aggregate increases, up to $50 \%$. Beyond this level, workability decreases. The workability of concrete could increase or decrease as the amount of fine recycled waste plastic aggregate increases depending on the particle shape, size, roughness, water-cement ratio and amount of cement paste.

- Plastic aggregate leads to a significant increase in air content of concrete due to the irregular shape, immiscibility of plastic and natural sand, and hydrophobic nature of plastic.

- Increase in the content of plastic aggregate reduces the density of concrete-the reduction is greater with bigger and flakier particles of plastic aggregate.

- A gradual decrease in the compressive strength development occurs with an increase in the content of plastic aggregate (both fine and coarse). Some studies, however, showed an increase in compressive strength for low levels of recycled waste plastic.

- When plastic aggregate fiber is used, a reduction in compressive strength with increase in fiber content and length is reported due to the increase in air content.

- The elastic modulus reduces linearly as the content of plastic aggregate increased. However, the drop in the elastic modulus is lower than the drop in compressive strength.

- A decrease int he flexural/splitting tensile strength of plastic aggregate concrete is reported. At moderate levels of replacement of natural aggregate with plastic aggregate (less than $20 \%$ waste plastic fiber), an increase in the flexural/tensile properties can be achieved.

- The ductility of concrete is significantly increased with the addition of plastic aggregate, up to $50 \%$. However, the fracture energy reduces with the increase in plastic aggregate content.

- Like the mechanical strength, the addition of waste plastic also contributes to the higher shrinkage, water absorption, chloride ingress, and lower thermal conductivity of concrete.

Finally, more research is required on influencing factors such as the treated plastic aggregates, shape and size aggregates, favorable mix compositions of concrete, curing condition, etc. to grow confidence on the use of plastic aggregates in concrete. Also, the long-term properties of concrete with plastic aggregates deserve more research. An example of possible application is in concrete pavements, where higher water absorption may help with proper drainage of rainwater. Although the strength of concrete is reduced with plastic aggregates, there could be other applications like temporary structures where the strength is still sufficient. Finally, there should be guidelines for using plastic aggregates in concrete. As it is found that the type, size, and shape of the plastic aggregates influence the concrete properties significantly, there must be guidelines for using plastic aggregates in concrete. 
Author Contributions: A.J.B. and S.C.P. defined the goals of the study. All authors performed the literature study. All authors have written the manuscript and commented on the final draft.

Funding: No specific funding was received for this research.

Conflicts of Interest: The authors declare no conflict of interest.

\section{References}

1. Panda, B.; Paul, S.C.; Lim, J.H.; Tay, Y.W.D.; Tan, M.J. Additive manufacturing of geopolymer for sustainable built environment. J. Clean. Prod. 2017, 167, 281-288. [CrossRef]

2. Paul, S.C.; van Zijl, G.P.A.G.; Tan, M.J.; Gibson, I. A review of 3D concrete printing systems and materials properties: Current status and future research prospects. Rapid Prototyp. J. 2018, 24, 784-798. [CrossRef]

3. Annapareddy, A.; Panda, B.; Ting, A.G.H.; Li, M.; Tan, M.J. Flow and mechanical properties of 3D printed cementitious material with recycled glass aggregates. In Proceedings of the 3rd International Conference on Progress in Additive Manufacturing (Pro-AM 2018), Singapore, 14-17 May 2018. [CrossRef]

4. Paul, S.C.; Šavija, B.; Babafemi, A.J. A comprehensive review on mechanical and durability properties of cement-based materials containing waste recycled glass. J. Clean. Prod. 2018, 198, 891-906. [CrossRef]

5. Bajracharya, R.M.; Manalo, A.C.; Karunasena, W.; Lau, K.T. An overview of mechanical properties and durability of glass-fibre reinforced recycled mixed plastic waste composites. Mater. Des. 2014, 62, 98-112. [CrossRef]

6. Ragaert, K.; Delva, L.; Van Geem, K. Mechanical and chemical recycling of solid plastic waste. Waste Manag. 2017, 69, 24-58. [CrossRef] [PubMed]

7. Geyer, R.; Jambeck, J.R.; Law, K.L. Production, use, and fate of all plastics ever made. Sci. Adv. 2017, 3, e1700782. [CrossRef] [PubMed]

8. Barnes, D.K.; Galgani, F.; Thompson, R.C.; Barlaz, M. Accumulation and fragmentation of plastic debris in global environments. Philos. Trans. R. Soc. B 2009, 364, 1985-1998. [CrossRef] [PubMed]

9. Gu, L.; Ozbakkaloglu, T. Use of recycled plastics in concrete: A critical review. Waste Manag. 2016, 51, $19-42$. [CrossRef] [PubMed]

10. Gourmelon, G. Global Plastic Production Rises, Recycling Lags. New Worldwatch Institute Analysis Explores Trends in Global Plastic Consumption and Recycling. Available online: http:/ wwww.worldwatch.org (accessed on 24 October 2018).

11. Hasanbeigi, A.; Price, L.; Lin, E. Emerging energy-efficiency and $\mathrm{CO}_{2}$ emission-reduction technologies for cement and concrete production: A technical review. Renew. Sustain. Energy Rev. 2012, 16, 6220-6238. [CrossRef]

12. Pacheco-Torgal, F.; Ding, Y.; Jalali, S. Properties and durability of concrete containing polymeric wastes (tyre rubber and polyethylene terephthalate bottles): An overview. Constr. Build. Mater. 2012, 30, 714-724. [CrossRef]

13. Sharma, R.; Bansal, P.P. Use of different forms of waste plastic in concrete-A review. J. Clean. Prod. 2016, 112, 473-482. [CrossRef]

14. Siddique, R.; Khatib, J.; Kaur, I. Use of recycled plastic in concrete: A review. Waste Manag. 2008, 28, 1835-1852. [CrossRef] [PubMed]

15. Jacob-Vaillancourt, C.; Sorelli, L. Characterization of concrete composites with recycled plastic aggregates from postconsumer material streams. Constr. Build. Mater. 2018, 182, 561-572. [CrossRef]

16. Ehrenstein, G.W.; Riedel, G.; Trawiel, P. Thermal Analysis of Plastics: Theory and Practice; Carl Hanser Verlag GmbH Co. KG: Munich, Germany, 2012.

17. Kim, K.-H.; Jeon, S.-E.; Kim, J.K.; Yang, S. An experimental study on thermal conductivity of concrete. Cem. Concr. Res. 2003, 33, 363-371. [CrossRef]

18. Zhang, H.; Šavija, B.; Chaves Figueiredo, S.; Lukovic, M.; Schlangen, E. Microscale testing and modelling of cement paste as basis for multi-scale modelling. Materials 2016, 9, 907. [CrossRef] [PubMed]

19. Mark, J.E. Physical Properties of Polymers Handbook; Springer: New York, NY, USA, 2007.

20. Bhogayata, A.C.; Arora, N.K. Impact strength, permeability and chemical resistance of concrete reinforced with metalized plastic waste fibers. Constr. Build. Mater. 2018, 161, 254-266. [CrossRef]

21. Bulut, H.A.; Şahin, R. A study on mechanical properties of polymer concrete containing electronic plastic waste. Compos. Struct. 2017, 178, 50-62. [CrossRef] 
22. Islam, M.J.; Meherier, M.S.; Islam, A.R. Effects of waste PET as coarse aggregate on the fresh and harden properties of concrete. Constr. Build. Mater. 2016, 125, 946-951. [CrossRef]

23. Akram, A.; Sasidhar, C.; Pasha, K.M. E-Waste Manage by Utilization of E-Plastics in Concrete Mixture as Coarse Aggregate Replacement. Int. J. Innov. Res. Sci. Eng. Technol. 2015, 4. [CrossRef]

24. Osei, D.Y. Experimental Investigation on Recycled Plastics as Aggregate in Concrete. Int. J. Struct. Civ. Eng. Res. 2014, 3, 168-174.

25. Rahmani, E.; Dehestani, M.; Beygi, M.H.A.; Allahyari, H.; Nikbin, I.M. On the mechanical properties of concrete containing waste PET particles. Constr. Build. Mater. 2013, 47, 1302-1308. [CrossRef]

26. Ferreira, L.; de Brito, J.; Saikia, N. Influence of curing conditions on the mechanical performance of concrete containing recycled plastic aggregate. Constr. Build. Mater. 2012, 36, 196-204. [CrossRef]

27. Lakshmi, R.; Nagan, S. Investigations on durability characteristics of E-plastic waste incorporated concrete. Asian J. Civ. Eng. 2011, 12, 773-787.

28. Hannawi, K.; Kamali-Bernard, S.; Prince, W. Physical and mechanical properties of mortars containing PET and PC waste aggregates. Waste Manag. 2010, 30, 2312-2320. [CrossRef] [PubMed]

29. Albano, C.; Camacho, N.; Hernandez, M.; Matheus, A.; Gutierrez, A. Influence of content and particle size of waste pet bottles on concrete behavior at different w/c ratios. Waste Manag. 2009, 29, 2707-2716. [CrossRef] [PubMed]

30. Choi, Y.W.; Moon, D.J.; Kim, Y.J.; Lachemi, M. Characteristics of mortar and concrete containing fine aggregate manufactured from recycled waste polyethylene terephthalate bottles. Constr. Build. Mater. 2009, 23, 2829-2835. [CrossRef]

31. Frigione, M. Recycling of PET bottles as fine aggregate in concrete. Waste Manag. 2010, 30, 1101-1106. [CrossRef] [PubMed]

32. Hama, S.M.; Hilal, N.N. Fresh properties of self-compacting concrete with plastic waste as partial replacement of sand. Int. J. Sustain. Built Environ. 2017, 6, 299-308. [CrossRef]

33. Jaivignesh, B.; Sofi, A. Study on Mechanical Properties of Concrete Using Plastic Waste as an Aggregate. In IOP Conference Series: Earth and Environmental Science; IOP Publishing: Bristol, UK, 2017.

34. Dhanani, M.G.V.; Bhimani, M.P.D. Effect of Use Plastic Aggregates as Partial Replacement of Natural Aggregates in Concrete with Plastic Fibres. Int. Res. J. Eng. Technol. 2016, 3, 2569-2573.

35. Ramesan, A.; Babu, S.S. Performance of light-weight concrete with plastic aggregate. Int. J. Eng. Res. Appl. 2015, 5, 105-110.

36. Babu, K.G.; Babu, D.S. Performance of fly ash concretes containing lightweight EPS aggregates. Cem. Concr. Compos. 2004, 26, 605-611. [CrossRef]

37. Tang, W.; Lo, Y.; Nadeem, A. Mechanical and drying shrinkage properties of structural-graded polystyrene aggregate concrete. Cem. Concr. Compos. 2008, 30, 403-409. [CrossRef]

38. Ismail, Z.Z.; Al-Hashmi, E.A. Use of waste plastic in concrete mixture as aggregate replacement. Waste Manag. 2008, 28, 2041-2047. [CrossRef] [PubMed]

39. Batayneh, M.; Marie, I.; Asi, I. Use of selected waste materials in concrete mixes. Waste Manag. 2007, 27, 1870-1876. [CrossRef] [PubMed]

40. Rai, B.; Rushad, S.T.; Kr, B.; Duggal, S.K. Study of waste plastic mix concrete with plasticizer. ISRN Civ. Eng. 2012, 2012. [CrossRef]

41. Silva, R.V.; de Brito, J.; Saikia, N. Influence of curing conditions on the durability-related performance of concrete made with selected plastic waste aggregates. Cem. Concr. Compos. 2013, 35, 23-31. [CrossRef]

42. Safi, B.; Saidi, M.; Aboutaleb, D.; Maallem, M. The use of plastic waste as fine aggregate in the self-compacting mortars: Effect on physical and mechanical properties. Constr. Build. Mater. 2013, 43, 436-442. [CrossRef]

43. Saikia, N.; de Brito, J. Mechanical properties and abrasion behaviour of concrete containing shredded PET bottle waste as a partial substitution of natural aggregate. Constr. Build. Mater. 2014, 52, 236-244. [CrossRef]

44. Bhogayata, A.C.; Arora, N.K. Fresh and strength properties of concrete reinforced with metalized plastic waste fibers. Constr. Build. Mater. 2017, 146, 455-463. [CrossRef]

45. Markovic, I. High-Performance Hybrid-Fibre Concrete: Development and Utilization; Delft University Press: Delft, The Netherlands, 2006.

46. Chen, C.C.; Jaffe, N.; Koppitz, M.; Weimer, W.; Polocoser, A. Concrete mixture with plastic as fine aggregate replacement. Int. J. Adv. Mech. Civ. Eng. 2015, 2, 49-53. 
47. Ravindrarajah, R.S. Bearing strength of concrete containing polystyrene aggregate. In Proceedings of the RILEM 8th International Conference Durability of Building Materials and Components, Vancouver, BC, Canada, 30 May-3 June 1999.

48. Iucolano, F.; Liguori, B.; Caputo, D.; Colangelo, F.; Cioffi, R. Recycled plastic aggregate in mortars composition: Effect on physical and mechanical properties. Mater. Des. 2013, 52, 916-922. [CrossRef]

49. Akçaözoğlu, S.; Akçaözoğlu, K.; Atiş, C.D. Thermal conductivity, compressive strength and ultrasonic wave velocity of cementitious composite containing waste PET lightweight aggregate (WPLA). Compos. Part B-Eng. 2013, 45, 721-726. [CrossRef]

50. Coppola, B.; Courard, L.; Michel, F.; Incarnato, L.; Scarfato, P.; Di Maio, L. Hygro-thermal and durability properties of a lightweight mortar made with foamed plastic waste aggregates. Constr. Build. Mater. 2018, 170, 200-206. [CrossRef]

51. Sosoi, G.; Barbuta, M.; Serbanoiu, A.A.; Babor, D.; Burlacu, A. Wastes as aggregate substitution in polymer concrete. Procedia Manuf. 2018, 22, 347-351. [CrossRef]

52. Kumar, K.S.; Baskar, K. Recycling of E-plastic waste as a construction material in developing countries. J. Mater. Cycles Waste Manag. 2015, 17, 718-724. [CrossRef]

53. Azhdarpour, A.M.; Nikoudel, M.R.; Taheri, M. The effect of using polyethylene terephthalate particles on physical and strength-related properties of concrete; a laboratory evaluation. Constr. Build. Mater. 2016, 109, 55-62. [CrossRef]

54. Yang, S.; Yue, X.; Liu, X.; Tong, Y. Properties of self-compacting lightweight concrete containing recycled plastic particles. Constr. Build. Mater. 2015, 84, 444-453. [CrossRef]

55. Premalatha, J.; Ahmed, S.A. Experimental Study on Concrete with Plastic Aggregates. Available online: http: / / www.internationaljournalssrg.org/IJCE/2017/Special-Issue/ICRTCETM/IJCE-ICRTCETM-P165.pdf (accessed on 24 October 2018).

56. Prakash, M.; Hemalatha, B. Replacement of waste material in concrete using recycled plastic. SSRG Int. J. Civ. Eng. (ICRTCETM-2017) 2017, 1, 9-14.

57. Hasan, A.; Islam, M.N.; Karim, M.R.; Habib, M.Z.; Wahid, M.F. Properties of concrete containing recycled plastic as coarse aggregate. In Proceedings of the International Conference on Recent Innovation in Civil Engineering for Sustainable Development (IICSD-2015), Gazipur, Bangladesh, 11-13 December 2015.

58. Mathew, P.; Varghese, S.; Paul, T.; Varghese, E. Recycled plastics as coarse aggregate for structural concrete. Int. J. Innov. Res. Sci. Eng. Technol. 2013, 2, 687-690.

59. Tamang, L.W.T.; Wangmo, T.; Darjay, K.T.; Phuntsho, K.S.; Namgyal, P.; Wangchuk, U. Use of plastics in concrete as coarse aggregate. Int. J. Educ. Appl. Res. 2017, 7, 9-13.

60. Kou, S.C.; Lee, G.; Poon, C.S.; Lai, W.L. Properties of lightweight aggregate concrete prepared with PVC granules derived from scraped PVC pipes. Waste Manag. 2009, 29, 621-628. [CrossRef] [PubMed]

61. Gesoglu, M.; Guneyisi, E.; Hansu, O.; Etli, S.; Alhassan, M. Mechanical and fracture characteristics of self-compacting concretes containing different percentage of plastic waste powder. Constr. Build. Mater. 2017, 140, 562-569. [CrossRef]

62. Aguayo, M.; Das, S.; Maroli, A.; Kabay, N.; Mertens, J.C.E.; Rajan, S.D.; Sant, G.; Chawla, N.; Neithalath, N. The influence of microencapsulated phase change material (PCM) characteristics on the microstructure and strength of cementitious composites: Experiments and finite element simulations. Cem. Concr. Compos. 2016, 73, 29-41. [CrossRef]

63. Mohammadhosseini, H.; Tahir, M.M.; Sam, A.R.M. The feasibility of improving impact resistance and strength properties of sustainable concrete composites by adding waste metalized plastic fibres. Constr. Build. Mater. 2018, 169, 223-236. [CrossRef]

64. Naik, T.R.; Singh, S.S.; Huber, C.O.; Brodersen, B.S. Use of post-consumer waste plastics in cement-based composites. Cem. Concr. Res. 1996, 26, 1489-1492. [CrossRef]

65. Bágel', L'.; Matiašovský, P. Surface Pretreatment-A Way to Effective Utilization of Waste Plastics as Concrete Aggregate, Review and first experiences. In Proceedings of the CESB10: Central Europe Towards Sustainable Building from Theory to Practice, Prague, Czech Republic, 30 June-2 July 2010.

66. Mehta, P.K.; Monteiro, P.J. Microstructure and properties of hardened concrete. In Concrete: Microstructure, Properties, and Materials; McGraw-Hill: New York, NY, USA, 2006; pp. 41-80, ISBN 978-0-07-146800-8. 
67. Fernandes, F.; Manari, S.; Aguayo, M.; Santos, K.; Oey, T.; Wei, Z.; Falzone, G.; Neithalath, N.; Sant, G. On the feasibility of using phase change materials (PCMs) to mitigate thermal cracking in cementitious materials. Cem. Concr. Compos. 2014, 51, 14-26. [CrossRef]

68. Šavija, B.; Zhang, H.; Schlangen, E. Influence of microencapsulated phase change material (PCM) addition on (micro) mechanical properties of cement paste. Materials 2017, 10, 863.

69. Liu, D.; Šavija, B.; Smith, G.E.; Flewitt, P.E.J.; Lowe, T.; Schlangen, E. Towards understanding the influence of porosity on mechanical and fracture behaviour of quasi-brittle materials: Experiments and modelling. Int. J. Fract. 2017, 205, 57-72. [CrossRef]

70. Hobbs, D. The dependence of the bulk modulus, Young's modulus, creep, shrinkage and thermal expansion of concrete upon aggregate volume concentration. Mater. Struct. 1971, 4, 107-114. [CrossRef]

71. Wyrzykowski, M.; Lura, P. Controlling the coefficient of thermal expansion of cementitious materials-A new application for superabsorbent polymers. Cem. Concr. Compos. 2013, 35, 49-58. [CrossRef]

72. Akçaözoğlu, S.; Atiş, C.D.; Akçaözoğlu, K. An investigation on the use of shredded waste PET bottles as aggregate in lightweight concrete. Waste Manag. 2010, 30, 285-290. [CrossRef] [PubMed]

73. Ruiz-Herrero, J.L.; Nieto, D.V.; Lopez-Gil, A.; Arranz, A.; Fernandez, A.; Lorenzana, A.; Meriono, S.; De Saja, J.A.; Rodriguez, M.A. Mechanical and thermal performance of concrete and mortar cellular materials containing plastic waste. Constr. Build. Mater. 2016, 104, 298-310. [CrossRef]

74. Hannawi, K.; Prince, W.; Kamali-Bernard, S. Strain capacity and cracking resistance improvement in mortars by adding plastic particles. J. Mater. Civ. Eng. 2012, 25, 1602-1610. [CrossRef]

75. Umadevi, R.; Kiran, C.R.S.; Sugandha, N. Recycled plastics and crushed rock powder as coarse aggregate and fine aggregate in structural concrete. Int. J. Adv. Res. Found. 2015, 2, 4-6.

76. Kumar, P.; Kumar, G. Effect of recycled plastic aggregates on concrete. Int. J. Sci. Res. 2016, 5, $912-915$.

77. Wittmann, F.; Mihashi, H.; Nomura, N. Size effect on fracture energy of concrete. Eng. Fract. Mech. 1990, 35, 107-115. [CrossRef]

78. Peterson, P. Fracture energy of concrete: Method of determination. Cem. Concr. Res. 1980, 10, 79-89. [CrossRef]

79. Hillerborg, A.; Modéer, M.; Petersson, P.E. Analysis of crack formation and crack growth in concrete by means of fracture mechanics and finite elements. Cem. Concr. Res. 1976, 6, 773-781. [CrossRef]

80. Neville, A.M.; Brooks, J.J. Concrete Technology; Longman Scientific and Technical: London, UK, 1987.

81. Jones, R.; Gatfield, E. Testing Concrete by Ultrasonic Pulse Velocity Technique. Available online: https: / / trid.trb.org/view/102365 (accessed on 25 October 2018).

82. Shariq, M.; Prasad, J.; Masood, A. Studies in ultrasonic pulse velocity of concrete containing GGBFS. Constr. Build. Mater. 2013, 40, 944-950. [CrossRef]

83. Raju, J.S.; Pandian, M.S. Mechanical Study on Concrete with Waste Plastic. Int. J. Res. Civ. Eng. Archit. Des. 2013, 1, 62-67.

84. Lakshmi, R.; Nagan, S. Studies on concrete containing E plastic waste. Int. J. Environ. Sci. 2010, 1, 270.

85. Senhadji, Y.; Escadeillas, G.; Benosman, A.S.; Mouli, M.; Khelafi, H.; Ould Kaci, S. Effect of incorporating PVC waste as aggregate on the physical, mechanical, and chloride ion penetration behavior of concrete. J. Adhes. Sci. Technol. 2015, 29, 625-640. [CrossRef]

86. Hossain, M.; Bhowmik, P.; Shaad, K. Use of waste plastic aggregation in concrete as a constituent material. Progress. Agric. 2016, 27, 383-391. [CrossRef]

87. Demirboga, R.; Kan, A. Thermal conductivity and shrinkage properties of modified waste polystyrene aggregate concretes. Constr. Build. Mater. 2012, 35, 730-734. [CrossRef]

88. Soroushian, P.; Eldarwish, A.I.; Tlili, A.; Ostowari, K. Experimental investigation of the optimized use of plastic flakes in normal-weight concrete. Mag. Concr. Res. 1999, 51, 27-33. [CrossRef]

89. Farhana, Z.F.; Kamarudin, H.; Rahmat, A.; Al Bakri, A.M. The relationship between water absorption and porosity for geopolymer paste. Mater. Sci. Forum 2015, 803, 166-172. [CrossRef]

90. Krus, M.; Hansen, K.K.; Künzel, H. Porosity and liquid absorption of cement paste. Mater. Struct. 1997, 30, 394-398. [CrossRef]

91. Bertolini, L.; Elsener, B.; Pedeferri, P.; Radaelli, E.; Polder, R.B. Corrosion of Steel in Concrete: Prevention, Diagnosis, Repair; John Wiley \& Sons: Hoboken, NJ, USA, 2013.

92. Broomfield, J.P. Corrosion of Steel in Concrete: Understanding, Investigation and Repair; CRC Press: Boca Raton, FL, USA, 2003. 
93. Šavija, B.; Lukovic, M.; Hosseini, S.A.S.; Pacheco, J.; Schlangen, E. Corrosion induced cover cracking studied by X-ray computed tomography, nanoindentation, and energy dispersive X-ray spectrometry (EDS). Mater. Struct. 2015, 48, 2043-2062. [CrossRef]

94. Michel, A.; Solgaard, A.O.S.; Pease, B.J.; Geiker, M.R.; Stang, H.; Olesen, J.F. Experimental investigation of the relation between damage at the concrete-steel interface and initiation of reinforcement corrosion in plain and fibre reinforced concrete. Corros. Sci. 2013, 77, 308-321. [CrossRef]

95. Alqahtani, F.K.; Ghataora, G.; Khan, M.I.; Dirar, S.; Kioul, A.; Al-Otaibi, M. Lightweight concrete containing recycled plastic aggregates. In Proceedings of the 2015 ICMEP, Paris, France, 13-14 April 2015.

96. Šavija, B.; Luković, M. Carbonation of cement paste: Understanding, challenges, and opportunities. Constr. Build. Mater. 2016, 117, 285-301. [CrossRef]

97. Saxena, R.; Siddique, S.; Gupta, T.; Sharma, R.K.; Chaudhary, S. Impact resistance and energy absorption capacity of concrete containing plastic waste. Constr. Build. Mater. 2018, 176, 415-421. [CrossRef]

98. Thorneycroft, J.; Orr, J.; Savoikar, P.; Ball, R.J. Performance of structural concrete with recycled plastic waste as a partial replacement for sand. Constr. Build. Mater. 2018, 161, 63-69. [CrossRef]

(C) 2018 by the authors. Licensee MDPI, Basel, Switzerland. This article is an open access article distributed under the terms and conditions of the Creative Commons Attribution (CC BY) license (http:/ / creativecommons.org/licenses/by/4.0/). 